\title{
Synthesis and Characterization of New Thiolated Chitosan Nanoparticles Obtained by Ionic Gelation Method
}

\author{
Reynaldo Esquivel, Josué Juárez, Mario Almada, Jaime Ibarra, and Miguel A. Valdez \\ Departamento de Investigación en Física, Universidad de Sonora, Rosales y Transversal, 83000 Hermosillo, SON, Mexico \\ Correspondence should be addressed to Reynaldo Esquivel; resquivelgo@conacyt.mx
}

Received 7 September 2015; Revised 17 November 2015; Accepted 17 November 2015

Academic Editor: Yulin Deng

Copyright ( 2015 Reynaldo Esquivel et al. This is an open access article distributed under the Creative Commons Attribution License, which permits unrestricted use, distribution, and reproduction in any medium, provided the original work is properly cited.

\begin{abstract}
We derivatized low molecular weight chitosan (LMWC) with 3-mercaptopropanoic acid (3-MPA) by a coupling reaction. The chemical modification of LMWC was characterized by Fourier transform infrared spectroscopy (FT-IR) and nuclear magnetic resonance, ${ }^{1} \mathrm{HNMR}$. We researched the influence of 3-MPA on the nanoparticles formation by ionic gelation method using sodium tripolyphosphate (TPP) as cross-linker reagent. In order to optimize the nanoparticles formation, we studied the effect of the $\mathrm{pH}$ solution and molar ratio on nanoparticles stability. Analyses of particle size, morphology, and surface charge were determined by dynamic light scattering, Atomic Force Microscopy, and zeta potential, respectively. It was found that formation of semispherical and stable nanoparticles was improved due to the chemical modification of chitosan. Optimized semispherical nanoparticles of thiolated chitosan were synthesized with the parameters ( $\mathrm{pH} 4.7$, molar ratios 1:106). Additionally, we reported the thermodynamic profile of the nanoparticles formation determined by isothermal titration calorimetry (ITC). The aggregation process achieved to form nanoparticles of thiolated and nonmodified chitosan consisted of two stages, considering one binding site model. Gibbs free energy $(\Delta G)$ and binding constant $\left(K_{a}\right)$ describe the aggregation process of thiolated chitosan/TPP, which is an initial reaction and followed by an endothermic stage. These results are promising for the possible application of these nanoparticles as nanocarriers and delivery systems.
\end{abstract}

\section{Introduction}

Nanotechnology is often used to solve problems in several areas as electronics, environment, agriculture, and biotechnology [1-4]. However, interesting properties of biopolymeric nanoparticles (BNP) have been widely explored in recent years by several research groups $[5,6]$. Nowadays, BNP have been used for the development of nanocarriers and drug delivery systems by improving their biocompatibility, specificity, and charge/release mechanism. These nanoparticles have several advantages as compatibility with the biological environment, controlled release of biomolecules, and improvement in cellular penetration. It is known that surface charge of the nanostructures plays an important role in adherence and cellular uptake mechanism through electrostatics interactions with cellular membranes. For this reason, several research groups have developed versatile methodologies to elaborate nanostructured materials that have a potential application in medical areas as therapeutic agent, contrast agent, among others [7-9]. To achieve this goal, it is important to use biocompatible polymers, for example, polyethylene glycol (PEG) [10], chitosan [11], and poly(lactic-co-glycolic acid) (PLGA) [12]. Nowadays, it is a challenge to design monodisperse and stable polymeric particles useful in certain applications, including cancer therapy and gene therapy.

Chitosan is a cationic linear polysaccharide obtained by segmental alkaline deacetylation of chitin. The structure of chitosan consists of units of $\mathrm{N}$-acetylglucosamine and glucosamine $[13,14]$. This polymer has been extensively studied due to the advantageous physicochemical properties such as high biocompatibility, nontoxicity, biodegradability, good solubility in water, and facility to be used as drug delivery system [15]. On the other hand, outstanding properties allow the use of chitosan as a material for potential medical applications [11]. Thus, numerous studies have highlighted 
the importance of size in nanoparticles synthetized from LMW chitosan by ionic gelation method; they showed the advantageous properties of nanosized particles.

Ionic gelation is based on electrostatic interactions between negatively charged functional groups that belong to the cross-linker agent. Frequently, tripolyphosphate (TPP) is used as well as positively charged amino groups of native chitosan [16]. Fan et al. [17] studied the influence of molar ratio $\mathrm{Ch} / \mathrm{TPP}, \mathrm{pH}$, and temperature on formation mechanism of nanoparticles of LMW chitosan. They reported NPs with hydrodynamic diameter of $138 \mathrm{~nm}$ and $\xi$-Potential value of $35 \mathrm{mV}$. The physicochemical properties depend highly on reaction parameters such as concentration of crosslinker agent, $\mathrm{pH}$, and ionic strength. However, they obtained microparticles at high amount of molecules of cross-linker (TPP). This problem can be overcome by structural modification of chitosan with functional groups that improve ionic interaction at the cross-linking process.

On the other hand, chemical modification of chitosan can be useful to enhance its physicochemical properties. Primary amino group $\left(-\mathrm{NH}_{2}\right)$ of the chitosan molecule is relatively easy to modify due to the electron-donating effect with various functional groups such as carboxylic acids and other reactive groups [18-20]. Several chemical routes have been developed to prepare derivative chitosan by nucleophilic reaction allowing the formation of imide (aldehyde reaction) and the corresponding amide with acyl reagent as carboxylic acids. Emmanuel et al. [21] reported the influence of structural modification by hydrophobization on chitosan backbone. They conjugated this biopolymer with different hydrocarbon chain length (twelve carbon chains) and researched the preparation of nanoparticles by ionic gelation method.

A further modification of positively charged amine group using thiol segments is widely used in order to enhance the bulk polymer properties $[22,23]$. Typical chitosan modification with thiol groups includes covalent attachment between the amine group and the mercaptocarboxylic acid by means of reaction intermediate from carbodiimide (EDAC) and $\mathrm{N}$ hydroxysuccinimide (NHS) [24-27]. For instance, Ko et al. [28] synthesized a novel thiolated chitosan by coupling reaction of 3-mercaptopropionic acid, LMWC/EDAC complex.

Thiolated chitosan has several advantageous features compared to native chitosan such as enhancement of solubility at low degree of substitution and mucoadhesive and cellular permeation properties. The chemical modification in certain chitosan chains allows the formation of internal and external bisulfide bonds. These interactions display enhancement of cohesive properties in the process of cross-linking; in this sense, the insertion of thiol groups results in improved internal interactions and high stability of microparticles [2931].

Zhu et al. [32] developed a new two-step method to synthesize thiolated low molecular weight chitosan with a high degree of substitution (Figure 1). They prepared spherical particles by ionotropic gelation method, using tripolyphosphate pentabasic as cross-linking reagent. DLS measurements show particle size corresponding to $D_{H}=265.7 \mathrm{~nm}$ and $\xi$ Potential $29.5 \mathrm{mV}$.
Isothermal titration calorimetry (ITC) is a physical technique used to determine thermodynamic properties in biomolecular reactions. Measuring absorbed or released heat of binding process allows determination of stoichiometry reaction $(N)$, enthalpy $(\Delta H)$, binding constant $\left(K_{a}\right)$, Gibbs free energy $(\Delta G)$, and entropy $(\Delta S)$. The thermodynamic profile of chitosan has been extensively studied in recent years; interactions between chitosan-insulin [33], chitosantrastuzumab antibody [34], and chitosan- $\mathrm{NaCl}$ [35] indicate important variations in the thermodynamic profile. This is attributed to the affinity of ligand-macromolecule interaction. On the other hand, few works have been produced in order to research the thermodynamics involved in NP's formation mechanism using chitosan or chitosan derivatives.

In this study, we synthesized thiolated chitosan and studied the preparation of nanoparticles by ionic gelation method. We also analyzed the impact of parameters including molar ratio $\mathrm{Ch}-\mathrm{SH} / \mathrm{TPP}$ and $\mathrm{pH}$ of the solution in order to develop nanoparticles with potential uses in biomedical application as drug nanocarriers systems. In addition, we determined the thermodynamic profile of the process on nanoparticles formation of Ch-SHSH/TPP by isothermal titration calorimetry.

\section{Experimental}

2.1. Materials. Low average molecular weight chitosan $(100,000 \mathrm{~g} / \mathrm{mol})$ with degree of deacetylation $(75-85 \%)$ and viscosity of 20-300 cP from Sigma-Aldrich. 3-Mercaptopropionic acid $\left(\mathrm{HSCH}_{2} \mathrm{CH}_{2} \mathrm{CO}_{2} \mathrm{H}\right) \mathrm{g} / \mathrm{mol}, \mathrm{N}$-(3-dimethylaminopropyl)- $\mathrm{N}^{\prime}$-ethylcarbodiimide hydrochloride EDAC, $\left(\mathrm{C}_{8} \mathrm{H} 17 \mathrm{~N}_{3} \cdot \mathrm{HCl}\right), \mathrm{N}$-hydroxysuccinimide NHS $\left(\mathrm{C}_{4} \mathrm{H}_{5} \mathrm{NO}_{3}\right)$, sodium hydroxide $(\mathrm{NaOH})$, acetic acid $\left(\mathrm{CH}_{3} \mathrm{CO}_{2} \mathrm{H}\right)$, pentasodium tripolyphosphate TPP $\left(\mathrm{Na}_{5} \mathrm{P}_{3} \mathrm{O}_{10}\right)$; all chemical reagents were purchased from Sigma-Aldrich Co., USA, and used as received. $\mathrm{H}_{2} \mathrm{O}$ was filtered with an Easy Pure/ Barnstead instrument with a resistivity of $17.5 \Omega-\mathrm{cm}$.

\subsection{Methods}

2.2.1. Synthesis of Thiolated Chitosan. The method of synthesis was adapted according to Ko et al. [28]. It includes two stages of reaction. In the first step, $0.104 \mathrm{mmol}$ of EDAC, $0.208 \mathrm{mmol}$ of 3-mercaptopropanoic acid, and $0.104 \mathrm{mmol}$ of NHS were poured in $100 \mathrm{~mL}$ three-neck flask previously charged with $2 \mathrm{~mL}$ of dimethylformamide. The mixture was kept at room temperature and under constant stirring overnight. The first step of reaction allows formation of Oacylisourea and activation of intermediate amine-reactive sulfo-NHS ester. Finally, $20 \mathrm{~mL}$ of chitosan solution $5 \%$ (v/w) was prepared using ultrapure water and $\mathrm{pH}$ was adjusted at 5.5 using $\mathrm{NaOH} 1 \mathrm{M}$. We added intermediate solution dropwise by syringe. The final mixture was stirred for 12 hours at room temperature. To eliminate the unbound 3MPPA and isolate the thiolated chitosan, the raw mixture was dialyzed (Cellu/Sep membrane dialysis $\mathrm{MWCO}=5000$ ) using $0.01 \mathrm{M} \mathrm{HCl}$ and deionized water. The product was precipitated with $50 \mathrm{~mL}$ of ethanol and the polymer was 

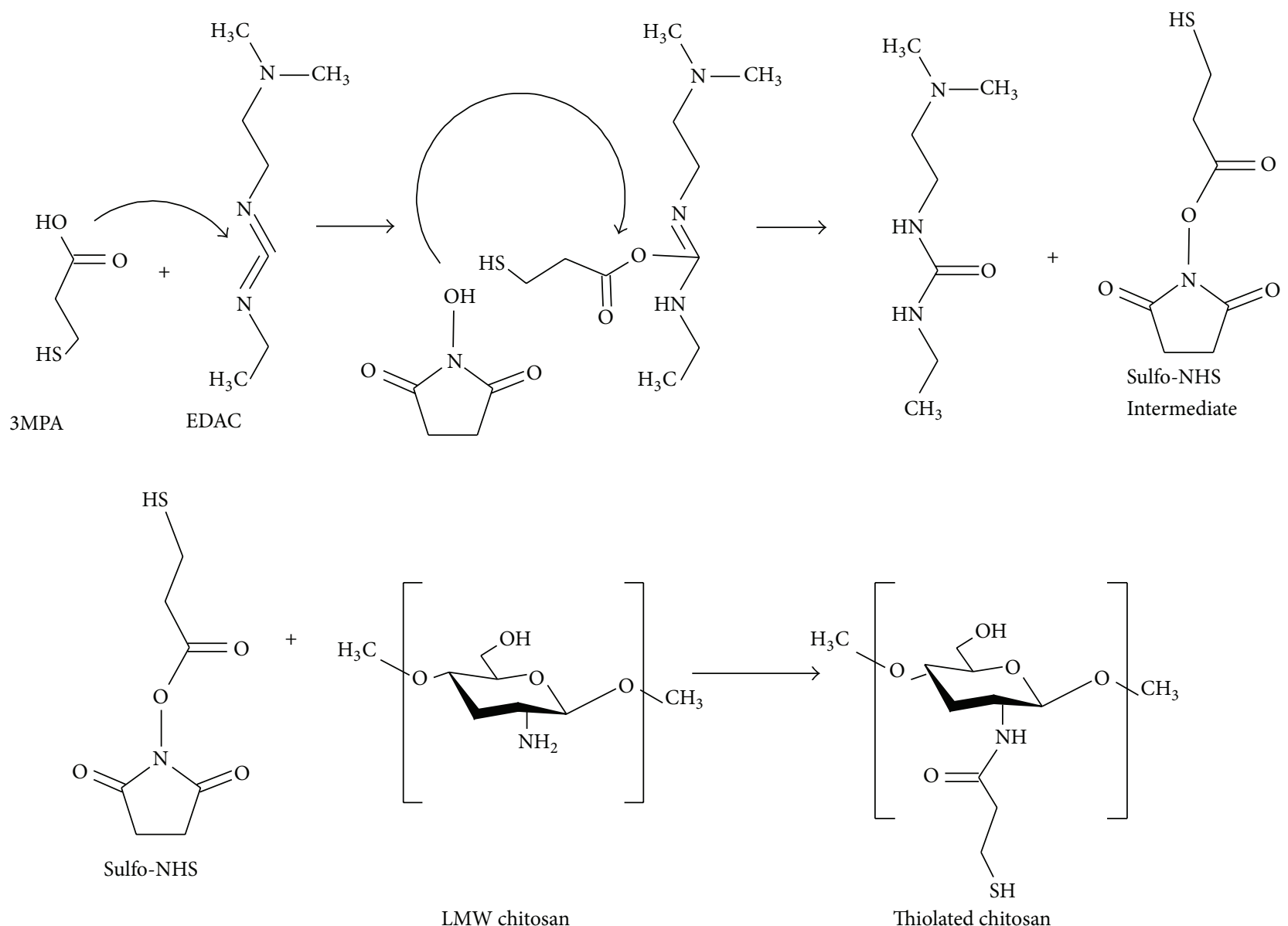

FIGURE 1: Reaction mechanism of thiolated chitosan.

separated by centrifugation ( $5,000 \mathrm{rpm}$ ) (3 times Allegra X-22 centrifuge, F1010 rotor). Derivative chitosan was lyophilized and then characterized by spectroscopic techniques to ensure pure chitosan.

2.2.2. Preparation of Thiolated Chitosan Nanoparticles. Chitosan thiolated nanoparticles were synthesized by adaptation of Zhu et al. method [32], based on the ionic gelation by cross-linking of TPP and free chains of chitosan. Synthesis of thiolated chitosan nanoparticles was as follows: thiolated chitosan $(0.5 \mathrm{mg} / \mathrm{mL})$ was dissolved in aqueous diluted solution of acetic acid $(2 \% \mathrm{w} / \mathrm{w})$ and stirred overnight at room temperature. The $\mathrm{pH}$ of the solution was around 3.9; this value was adjusted to 4.7 by addition of minimal amounts of $\mathrm{NaOH}$ $2 \mathrm{M}$ solution. After that, aqueous solution of tripolyphosphate was prepared at concentration of $0.5 \mathrm{mg} / \mathrm{mL}$ using ultrapure water, and then $3.3 \mathrm{~mL}$ of this solution was stored and cooled in a fridge at $0-2^{\circ} \mathrm{C}$ for 4 hours. The solution of thiolated chitosan was placed in preheated water bath at $60^{\circ} \mathrm{C}$ for 10 minutes under constant stirring. Then this solution was transferred to an ice bath and, immediately, TPP solution was added to the mixture and stirred for ten minutes. The ice bath was removed and the obtained opalescent suspension was further stirred for fifteen minutes at room temperature. The synthesized nanoparticles were centrifuged at $15000 \mathrm{rpm}$ by 30 minutes and resuspended twice in ultrapure water for physicochemical characterizations. We used the same procedure with different molar ratio Ch-SH/TPP (1:68 to $1: 109)$.

\subsection{Characterization}

2.3.1. Fourier Transform Infrared Spectroscopy (FT-IR). Fourier transform infrared spectra were collected from spectrometer Spectrum Two (Perkin-Elmer, USA) equipped with an accessory of a single diamond Attenuated Total Reflectance (ATR) with range $8300-350 \mathrm{~cm}^{-1}$ and interferometer with variable speed of $0.1,0.2,0.5,1,2$, and $4 \mathrm{~cm} / \mathrm{s}$. IR Beam diameter is from 2 to $11 \mathrm{~mm}$. The IR spectra were collected sixteen times (spectral resolution $4 \mathrm{~cm}^{-1}$ ) and analyzed using Spectrum software. Chitosan was analyzed before and after derivatization with thiol groups. Spectra were recorded and analyzed for signal assignation.

2.4. Nuclear Magnetic Resonance $\left({ }^{1} H N M R\right)$. High resolution ${ }^{1}$ HNMR spectra were recorded from Bruker (Avance, $400 \mathrm{MHz}$ ) ultra-shielded standard-bore magnet equipped with a $5 \mathrm{~mm}$ BBFO probe and a Bruker Sample Case autosampler with 24 positions. Native and thiolated chitosan were 
analyzed in order to confirm structural modification in pure chitosan. All the samples were prepared dissolving $8 \mathrm{mg}$ of the polymer with $2 \%(\mathrm{v} / \mathrm{v})$ of $\mathrm{DCl} / \mathrm{D}_{2} \mathrm{O}$ mixture. The solution was heated at $50^{\circ} \mathrm{C}$ to ensure complete solubility. Results were analyzed in $\mathrm{ACD} / \mathrm{labs}$ software for spectra calibration and peak assignment.

2.4.1. Size Measurements. Dynamic light scattering (DLS) measurements were performed in Zetasizer Nano $Z$ equipment (Malvern US), using digital autocorrelator $25 \mathrm{~ns}$ to $8000 \mathrm{~s}$, max 4000 channels with measurement range of $0.3 \mathrm{~nm}-10.0$ microns, equipped with temperature control set to $0^{\circ} \mathrm{C}$ to $90^{\circ} \mathrm{C} \pm 0.1^{\circ} \mathrm{C}$, with He-Ne laser $4 \mathrm{~mW} 633 \mathrm{~nm}$ and purge system using dry air. The method used is Noninvasive Back-Scatter (NIBS) technology. The relationship between the size of a particle and its speed due to Brownian motions is defined in the Stokes-Einstein equation:

$$
D=\frac{K_{B} T}{6 \pi \eta R},
$$

where $D$ is diffusion constant, $K_{B}$ is Boltzmann's constant, $T$ is the absolute temperature, $\eta$ is dynamic viscosity, and $R$ is hydrodynamic radius. The analysis was carried out in triplicate in diluted suspensions of nanoparticles.

2.4.2. Zeta Potential Determination. Determination of zeta potential was carried out in Zetasizer Nano $Z$ with light source He-Ne laser $633 \mathrm{~nm}$, max $4 \mathrm{~mW}$ with measurement accuracy $0.12 \mu \mathrm{m} \cdot \mathrm{cm} / \mathrm{V} \cdot \mathrm{s}$ for aqueous systems using NIST SRM1980 standard reference material. The Zetasizer Nano series calculates the zeta potential by determining the electrophoretic mobility and then applying the Henry equation:

$$
U_{E}=\frac{2 \varepsilon Z f(k a)}{3 \eta},
$$

where $U_{E}$ is the electrophoretic mobility, $\varepsilon$ is the dielectric constant, $Z$ is the zeta potential, $\eta$ is the absolute zero-shear viscosity of the medium, $f(k a)$ is the Henry function, and $k a$ is a measure of the ratio of the particle radius to the Debye length. The velocity of a particle in an electric field is commonly referred to as its electrophoretic mobility. The sample was analyzed in quartz cuvettes using a small amount of colloidal suspension. Zeta potential and standard deviation were reported.

2.5. Atomic Force Microscopy (AFM). AFM imaging was performed by an AFM instrument (JSPM-4210, JEOL) in no contact mode. A cantilever (OMCL-AC160TS, Olympus) with resonant frequency of $300 \mathrm{kHz}$ and spring constant of $42 \mathrm{~N} / \mathrm{m}$ was used. Resuspended thiolated and native nanoparticles were diluted in ultrapure water 1:100 and poured in a new cleaved mica surface. Images were treated and analyzed in order to elucidate morphology and size of particles.

2.6. Isothermal Titration Calorimetry (ITC). Isothermal titration was developed by MicroCal VP-ITC with automatic injection syringe system ( $300 \mu \mathrm{L}$ max). Isothermal titration

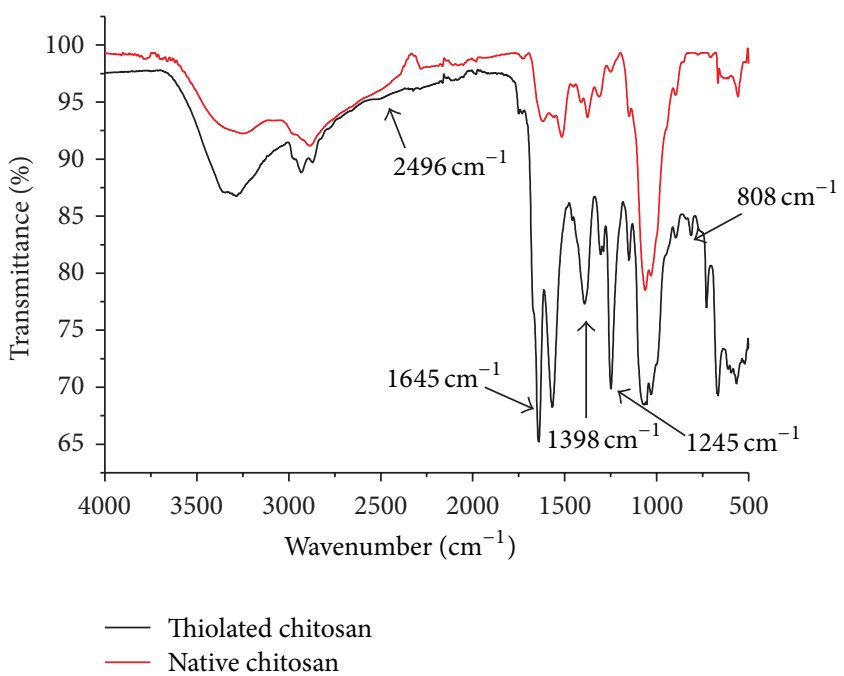

FIGURE 2: FT-IR spectra of thiolated chitosan and native chitosan.

calorimetry (ITC) measures heat change in an ITC experiment and enables accurate determination of binding constants $\left(K_{D}\right)$, interaction stoichiometry $(N)$, enthalpy $(\Delta H)$, and entropy $(\Delta S)$, providing a complete thermodynamic profile of the molecular interactions in a single experiment. Experiments of titration for the nanoparticles synthesis from native and thiolated chitosans were performed as follows: sample cell was filled with $1.4584 \mathrm{~mL}$ of solution $1.6 \times 10^{-3} \mathrm{mM}$ of low molecular weight chitosan at $\mathrm{pH} 4.7$; acetic acid $30 \mathrm{mM}$ solution at the same $\mathrm{pH}$ was charged in a reference cell. All solutions were previously degasified under vacuum. Sampler micropipette was loaded with TPP $0.98 \mathrm{mM}$ solution, using ultra-pure water $(18.3 \mu-\Omega-\mathrm{cm})$. The experiment was performed with 26 injections of $10 \mu \mathrm{L}$ of TPP solution every 300 seconds and an initial injection of $2 \mu \mathrm{L}$. Raw data were treated with MicroCal ORIGIN version 7.0 software for background subtraction and mathematical modeling.

\section{Results and Discussion}

\subsection{Spectroscopy}

3.1.1. Fourier Transform Infrared (FT-IR). Comparative FTIR spectra of native LMWC and thiolated chitosan Ch-SH are shown in Figure 2. Results of the analysis indicate the successful modification of native chitosan selectively on the amine groups, by the reaction between the primary amine groups of chitosan and the carboxylic groups of the mercaptopropionic acid resulting in amide group. The presence of the peak at $1645 \mathrm{~cm}^{-1}(\mathrm{C}=\mathrm{O}$ stretching amides $)$ and deformation of the signal at $3225 \mathrm{~cm}^{-1}$ (-NH stretching amide) proves the formation of (C-NH) amide bond. The peak at $2496 \mathrm{~cm}^{-1}$ due to $(-\mathrm{SH})$ stretching confirms the presence of thiols as terminal group linked to the chitosan molecule. The presence of the peaks at $808 \mathrm{~cm}^{-1}$ (S-S bisulfide bond) and $1245 \mathrm{~cm}^{-1}$ (C$\mathrm{SH}$ stretching) in modified chitosan confirms the existence of mercaptans since such peaks are not seen in native chitosan 


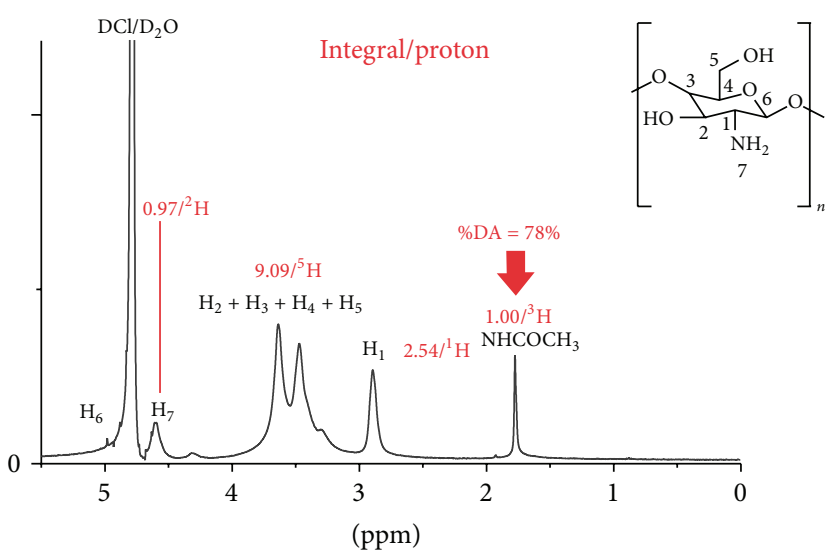

(a)

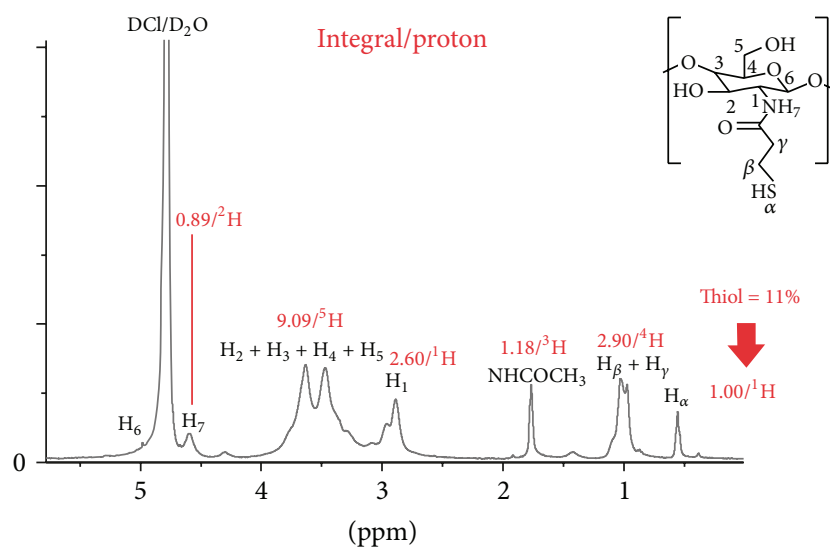

(b)

Figure 3: ${ }^{1} \mathrm{HNMR}$ spectra of native (a) and thiolated (b) chitosan in $\mathrm{DCl} / \mathrm{D}_{2} \mathrm{O}$.

spectra. Compared to the results already published by Zhu et al. [32], they reported modification of native chitosan using thioglycolic acid; structural characterization by FTIR spectra shows typical peaks of mercaptans at $2680 \mathrm{~cm}^{-1}$ (SH stretching), $1250 \mathrm{~cm}^{-1}$ corresponding to the vibration of C-SH bond, and small peak at $2923 \mathrm{~cm}^{-1}$ associated with stretching of C-H groups. FT-IR analysis confirms the success of modification of native chitosan by addition reaction and a complementary analysis of derivative compound was carried out by ${ }^{1} \mathrm{H}$ proton magnetic resonance $\left({ }^{1} \mathrm{HNMR}\right)$.

3.1.2. ${ }^{1}$ H Proton Magnetic Resonance ( $\left.{ }^{1} H N M R\right)$. Functionalized and native LMWC were characterized by ${ }^{1} \mathrm{HNMR}$ spectroscopy under the same conditions; corresponding ${ }^{1} \mathrm{HNMR}$ spectra in $\mathrm{DCl} 10 \mathrm{mM}$ of thiolated and native LMWC are shown in Figure 3. In the NMR spectrum of the thiolated chitosan, there still appeared some signals similar to those native chitosan. The appearance of signals at $1.92 \mathrm{ppm}$ $\left(\mathrm{NHCOCH}_{3}\right), 2.98 \mathrm{ppm}\left(\mathrm{H}_{1}\right)$ due to the protons - $\mathrm{CH}-$, and 3.6 to $3.8 \mathrm{ppm}\left(\mathrm{H}_{2}, \mathrm{H}_{3}, \mathrm{H}_{4}\right.$, and $\left.\mathrm{H}_{5}\right)$ due to $\mathrm{CH}$ protons confirms the presence of the glucosamide moiety. Decrease of signal at $4.6 \mathrm{ppm}\left(\mathrm{H}_{7}, \mathrm{NH}_{2}\right)$ and new peak at $0.52 \mathrm{ppm}\left(\mathrm{H}_{\alpha}\right)$ $\left(-\mathrm{CH}_{2}-\mathrm{SH}\right)$ are in accordance with the formation of thiolated chitosan. The signal at $0.92\left(\mathrm{H}_{\gamma}\right)$ to $1.10 \mathrm{ppm}\left(\mathrm{H}_{\beta}\right)$ corresponds to protons of the new alkyl chain $\left(-\mathrm{CH}_{2}\right)$. Han et al. [36] synthesized thiolated derivative chitosan where structural characterization by ${ }^{1} \mathrm{HNMR}$ shows a peak at $2.1 \mathrm{ppm}$ that corresponds to the protons of $-\mathrm{CH}_{2}$ - of the new side chain; a small signal was observed at $4.6 \mathrm{ppm}$ due to the remaining protons of amine group $\left(-\mathrm{NH}_{2}-\right)$ after the derivatization of native chitosan. Intense peak at $4.8 \mathrm{ppm}$ was related to the proton $\mathrm{H}_{1}$ of hydroxyl group. We consider that a high degree of derivatization could lead to insoluble systems due to the hydrocarbon chains. Thus, the ${ }^{1}$ HNMR spectra proved the successful attachment of mercaptopropionic acid to native LMW chitosan and also confirmed the presence of free thiol groups.
3.1.3. Quantification of Chitosan Transformation. Consider the following equation:

$$
\% \text { Yield }=\left(\frac{A_{\alpha}}{A_{\mathrm{H}_{2}-\mathrm{H}_{5}}}\right) \times 100,
$$

where $A_{\alpha}$ is area of signal $\mathrm{SH}$ and $A_{\mathrm{H}_{2}-\mathrm{H}_{5}}$ is area of signal $\mathrm{H}_{2}-\mathrm{H}_{5}$.

Nuclear magnetic resonance of proton $\left({ }^{1} \mathrm{HNMR}\right)$ was employed in quantitative analysis and structural determination of modification of native chitosan. The degree of modification of native chitosan with thiol groups $(\mathrm{SH})$ was calculated from the area of the signal $\mathrm{H}_{\alpha}\left(A_{\mathrm{SH}}\right)$ and the sum of the areas from signals $\mathrm{H}_{2}$ to $\mathrm{H}_{5}\left(A_{\mathrm{H}_{2}-\mathrm{H}_{5}}\right)$ at the ${ }^{1}$ HNMR spectra (1) [37]. The amount of free thiol groups was determined by ${ }^{1} \mathrm{HNMR}$, and this value reached $11 \%$ of substitution on amine groups. The low degree of modification of the native chitosan avoids the insolubility problems of modification above $40 \%$.

\subsection{Study of Ch-SH/TPP Molar Ratio on NP's Formation}

3.2.1. Effect on the Size of Nanoparticles. We researched the influence of TPP at different molar ratio with respect to thiolated Ch-SH $(1: 71$ to $1: 114 \mathrm{Ch}-\mathrm{SH} / \mathrm{TPP} 0.5 \mathrm{mg} / \mathrm{mL})$ on the particle size. The obtained results are presented in Table 1. From DLS data (Figure 4), we noticed an evident decrease of hydrodynamic diameter of nanoparticles by increasing the amount of TPP. This fact demonstrates the influence of the amount of TPP units on the NP's size. The first decrement of particle size at molar ratio $1: 71$ to $1: 86$ (Table 1) was from $195 \mathrm{~nm}$ to $168 \mathrm{~nm}$; consecutively the size of nanoparticles decreased to $142 \mathrm{~nm}$. When the molar ratio of $\mathrm{Ch}-\mathrm{SH} / \mathrm{TPP}$ was 1:71, the result was a slight opalescent suspension, indicating that the density of TPP is barely enough for crosslinking. This behavior was confirmed by AFM.

Chitosan chains have high quantity of reactive amine groups, which provides potential cross-linking sites. Thereby, 
TABLE 1: $\xi$-Potential and size, effect of $\mathrm{Ch}-\mathrm{SH} / \mathrm{TPP}$ molar ratio concentration $0.5 \mathrm{mg} / \mathrm{mL}$.

\begin{tabular}{lccccc}
\hline Sample & Molar ratio & $\mathrm{pH}$ & $\begin{array}{c}\xi \text {-Potential } \\
(\mathrm{mV})\end{array}$ & $\begin{array}{c}\text { Size } \\
(\mathrm{nm})\end{array}$ & PDI \\
\hline $\mathrm{NPT}_{1}$ & $1: 114$ & 4.7 & 30 & 142 & 0.16 \\
$\mathrm{NPT}_{2}$ & $1: 106$ & 4.7 & 34 & 137 & 0.16 \\
$\mathrm{NPT}_{3}$ & $1: 100$ & 4.7 & 31 & 162 & 0.14 \\
$\mathrm{NPT}_{4}$ & $1: 94$ & 4.7 & 39 & 160 & 0.18 \\
$\mathrm{NPT}_{5}$ & $1: 86$ & 4.7 & 40 & 168 & 0.18 \\
$\mathrm{NPT}_{6}$ & $1: 77$ & 4.7 & 39 & 200 & 0.18 \\
$\mathrm{NPT}_{7}$ & $1: 71$ & 4.7 & 40 & 195 & 0.20 \\
\hline
\end{tabular}

the molar ratio of Ch-SH/TPP is related with the crosslinking degree, but it is limited by the aggregation phenomena at high concentration of the polyanion. In this sense, when the amount of TPP molecules of Ch-SH/TPP reached 1:114, a decrease in the particle size was observed due to a higher amount of TPP molecules, which promote the nanoparticle formation and provide structural stability of chitosan nanoparticles by interaction between the TPP molecules and positively charged free chitosan chains, shrinking chitosan NPs. Fan et al. [17] prepared nanoparticles from native chitosan for a specific range from 1:86 to 1:90 of molar ratio of TPP/Ch; their results showed that above molar ratio of 1:96, large microparticles are produced, thus limiting the repulsion forces between the particles leading to the flocculation and subsequent precipitation. Modulation of particle size prepared from modified chitosan is an important parameter for cellular internalization. Cells can internalize particles under $1 \mu \mathrm{m}$ in diameter by different pathways. For example, particles as large as $500 \mathrm{~nm}$ could be internalized via an energetic dependant mechanism. In contrast, particles under $200 \mathrm{~nm}$ in size can lead to a nonenergetic endocytosis pathway. The modulation of nanoparticles of thiolated chitosan $(142 \mathrm{~nm}$ to $195 \mathrm{~nm})$ is an advantageous factor in order to design nanostructures for specific application.

In this work, we elaborated nanoparticles using thiolated chitosan even at high concentration of TPP molecules. Thereby, at molar ratio 1:94, unimodal nanoparticles of thiolated chitosan were formed. The size of these particles was modulated from $142 \mathrm{~nm}$ at molar ratio 1:114 (Ch-SH/TPP) to $195 \mathrm{~nm}$ prepared with molar ratio 1:71 (Ch-SH/TPP). We associate the stability of thiolated chitosan NPS at highest amount of TPP with the formation of external and internal disulfide bonds; in this manner formation on nanoparticles is stabilized by stronger interactions from disulfide bonds $[38,39]$.

3.2.2. Effect on $\xi$-Potential. In this section, we analyzed the effect of different molar ratio Ch-SH/TPP (1:71 to $1: 114$ ChSH/TPP $0.5 \mathrm{mg} / \mathrm{mL}$ ) on the zeta potential of nanoparticles. According to the results shown in Table 1, we observed an important decrease of zeta potential by increasing the amount of TPP molecules. Zeta potential decreased proportionally to the increase of TPP molecules from $40 \mathrm{mV}$ to $30 \mathrm{mV}$; this is due to the charge neutralization reaction between amine groups of chitosan and free chains and negative charges of TPP. For all cases, zeta potential values were positive and relatively high (above $30 \mathrm{mV}$ ). Particles showed good stability at room temperature.

Zeta potential is related to the repulsive or attractive interactions between adjacent particles. For biomedical application, the modulation of charge is important in order to design nanodevice able to interact with positive or negative barriers or membranes.

3.2.3. Effect on Morphology. An analysis of morphology was carried out by Atomic Force Microscopy (AFM). Figure 5 shows AFM micrographs for NPs with different molar ratio. In the set of micrographs, it is possible to observe the morphological evolution of thiolated chitosan nanoparticles as function of TPP concentration. Figure 5(a) (Ch-SH/TPP $1: 114)$ shows semispherical nanoparticles with an average size of $80 \mathrm{~nm}$. In this sense, it is known that intra- and intermolecular interaction between TPP and chitosan are responsible for the ionic gelation even at a low concentration of TPP.

Figure 5(b) presents monodisperse particles with sizes between $140 \mathrm{~nm}$ and $200 \mathrm{~nm}$ (Figure 6) corresponding to the DLS measurements. In Figure 5(c), it can be seen that at this concentration of anionic cross-linker, morphology was semispherical, maybe due to the decrease of cross-linking degree of the chitosan-TPP reaction. It is important that when the molar ratio of Ch-SH/TPP was 1: 94, Figure 5(d), the population of nanoparticles were again polydisperse. We observed that a high quantity of molecules of TPP could change the structural conformation of chitosan chains and significantly reduce the solubility of the chitosan [40,41], thus favoring aggregation.

We reduced the amount of TPP molecules (molar ratio $1: 77$ and molar ratio 1:71); under this condition, we obtained nanoparticles with size between 120 to $150 \mathrm{~nm}$. The decrease of particle size is compared with the results obtained by Weng F. et al. (2012). They determined the best condition of molar ratio of Ch/TPP (1:90) to obtain chitosan nanoparticles. At molar relation Ch/TPP 1:96, the size increased to $240 \mathrm{~nm}$; probably the excessive concentration of TPP limited the intramolecular cross-linking. An overall conclusion of our results is that it is possible to modulate size and charge of nanoparticles between $100 \mathrm{~nm}$ and $200 \mathrm{~nm}$, and between $30 \mathrm{mV}$ and $40 \mathrm{mV}$, respectively. A greater dependency of the formulation parameters was observed in the morphology and population of nanoparticles.

\subsection{Effect of pH of Thiolated Chitosan Solution on NP's Formation}

3.3.1. Effect on Particle Size. In order to determine the feasibility to prepare thiolated chitosan nanoparticles by ionic gelation, the $\mathrm{pH}$ of chitosan solution was varied from 4 to 5.3. Chitosan is a weak polyelectrolyte with $\mathrm{p} K_{a}$ near to (6.5) due to the amine groups and insoluble at alkaline and neutral $\mathrm{pH}$. At acid medium $\mathrm{pH}$, the primary amine can be protonated by hydrogen ions and thus acquires positive charge density. 

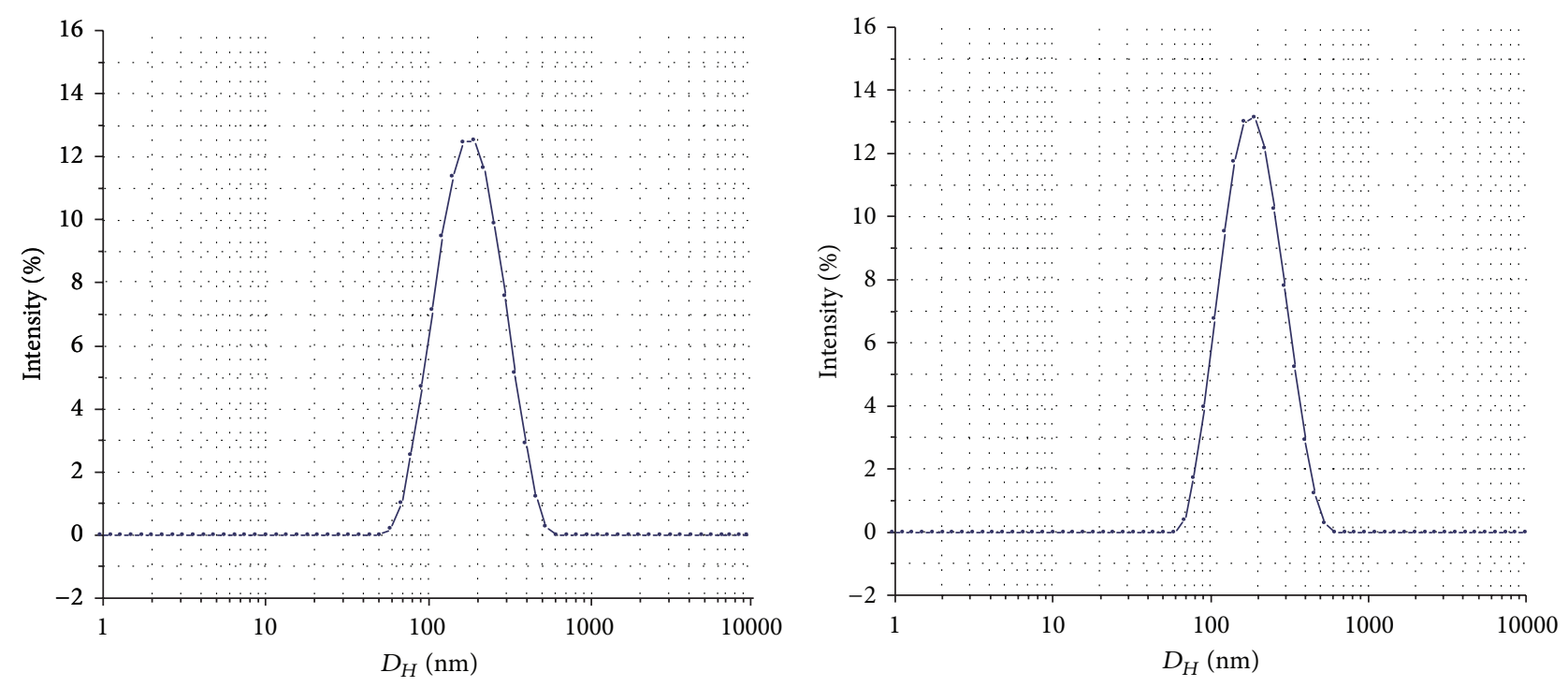

_— Molar ratio 1:71
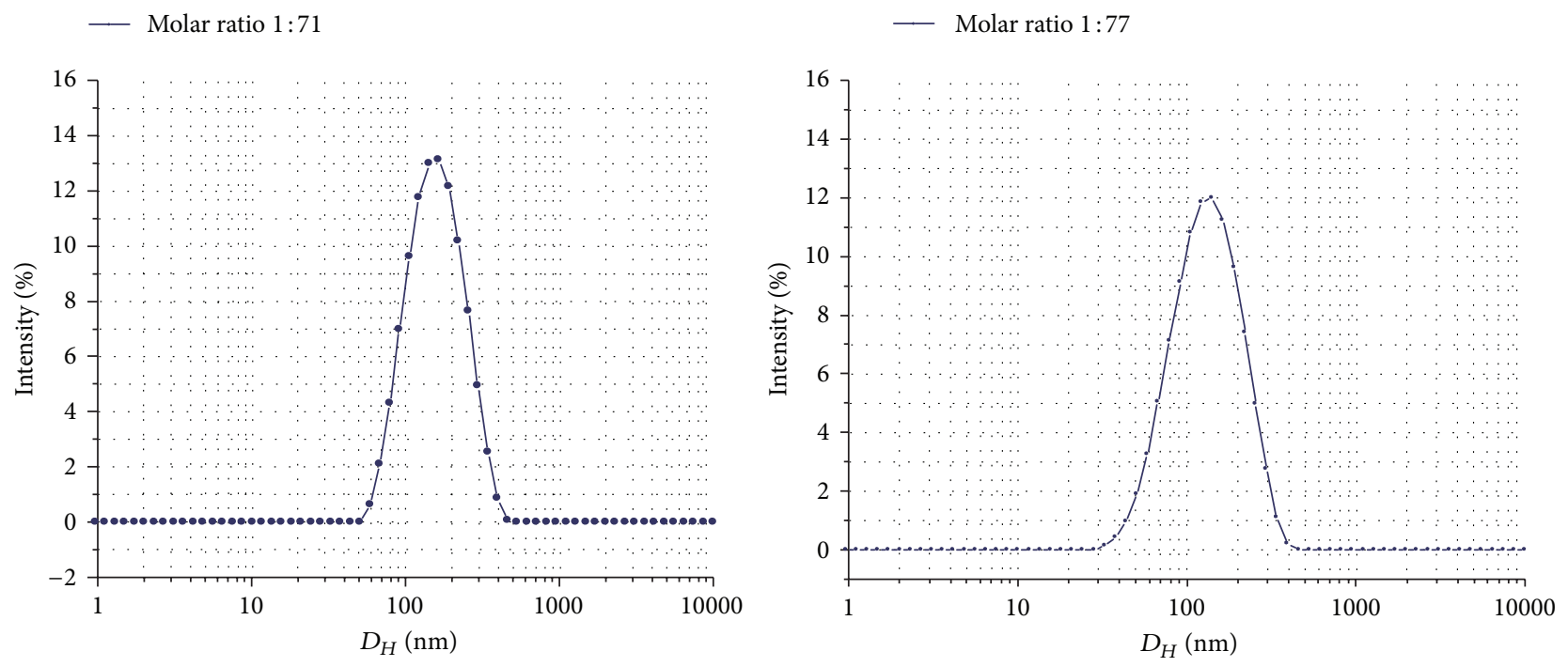

- - Molar ratio 1:86

—— Molar ratio 1:114
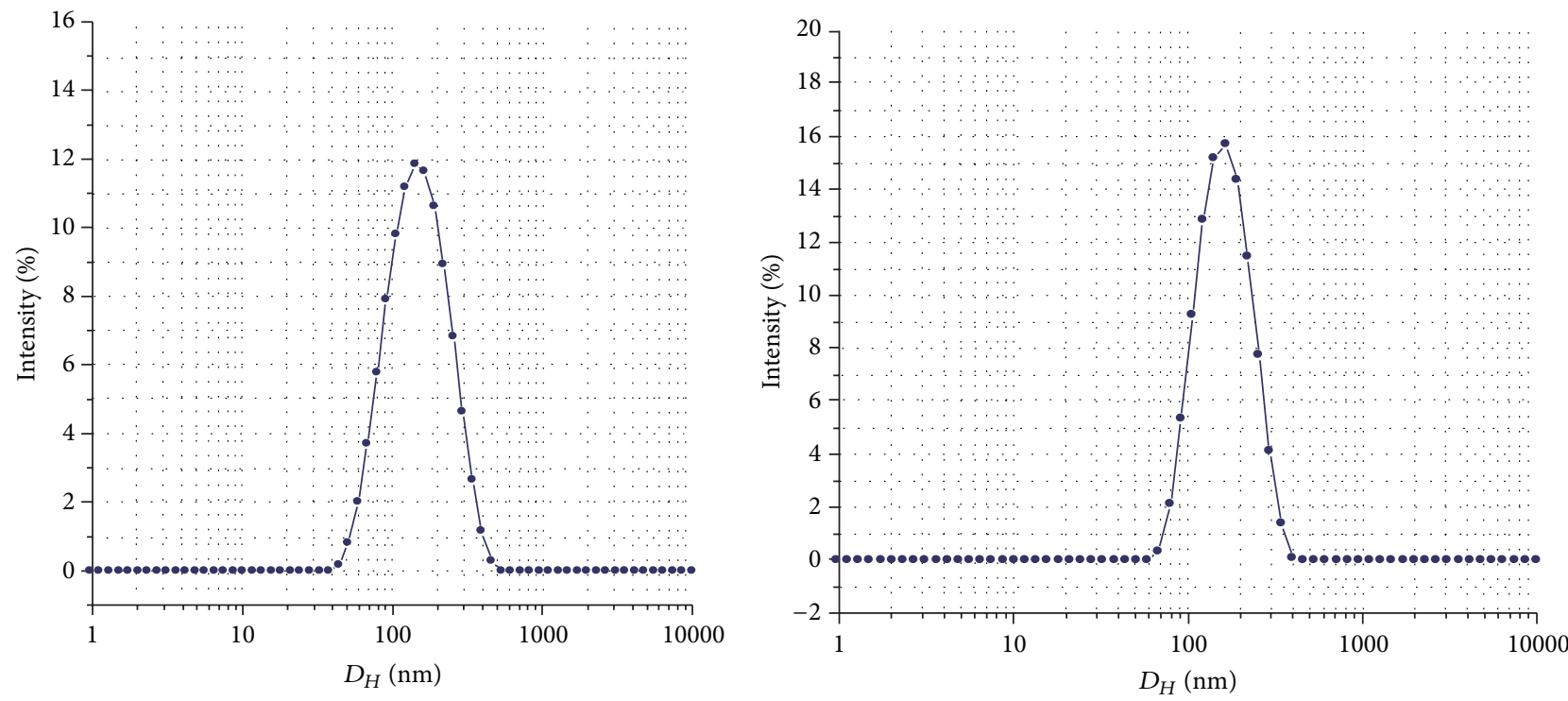

- Molar ratio 1:94

- Molar ratio 1:100

FIGURE 4: Continued. 


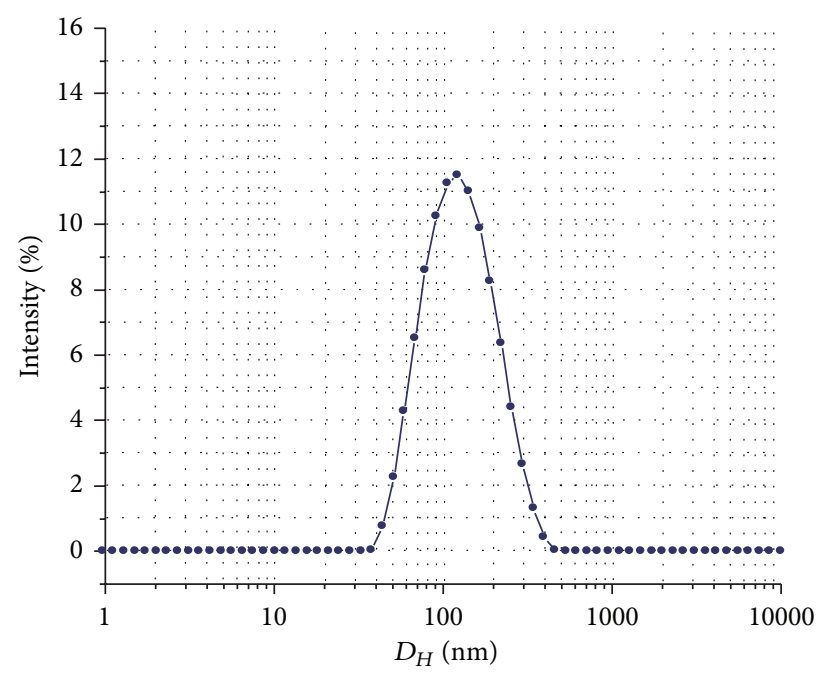

FIgURE 4: Particle size distribution of chitosan SH/TPP nanoparticles prepared with different molar ratio.

TABLE 2: $\xi$-Potential and size, effect of $\mathrm{pH}$.

\begin{tabular}{lccccc}
\hline Sample & Molar ratio & $\mathrm{pH}$ & $\begin{array}{c}\xi \text {-Potential } \\
\mathrm{mV}\end{array}$ & $\begin{array}{c}\text { Size } \\
\mathrm{nm}\end{array}$ & PDI \\
\hline $\mathrm{NPpH}_{1}$ & $1: 94$ & 4 & 38 & 153 & 0.11 \\
$\mathrm{NPpH}_{2}$ & $1: 94$ & 4.3 & 38 & 184 & 0.11 \\
$\mathrm{NPpH}_{3}$ & $1: 94$ & 4.5 & 42 & 189 & 0.07 \\
$\mathrm{NPpH}_{4}$ & $1: 94$ & 4.7 & 39 & 162 & 0.18 \\
$\mathrm{NPpH}_{5}$ & $1: 94$ & 5 & 40 & 215 & 0.21 \\
$\mathrm{NPpH}_{6}$ & $1: 94$ & 5.3 & 33 & 220 & 0.15 \\
\hline
\end{tabular}

Our study was based on controlling the acid conditions of the solution; in this way, the dependence of the degree of protonation of amine groups of chitosan on the conformational arrangements of free chains is analyzed. To assess the effect of $\mathrm{pH}$ on NP's formation, we selected six different $\mathrm{pH}$ values $(4,4.3,4.5,4.7,5.0$, and 5.3), and measured zeta potential, hydrodynamic diameter and observed morphology.

Figure 7 shows the DLS profile for each experiment, we observed monodisperse curve, and PDI values below $25 \%$. Table 2 shows that hydrodynamic diameter increases significantly as $\mathrm{pH}$ takes a value of 5.3. At the highest $\mathrm{pH}$ measured (5.3), microaggregation phenomenon occurred due to nearness $\mathrm{p} K_{a}$ of the chitosan $\left(\mathrm{p} K_{a}=6.3\right)$ [42]. However, at low $\mathrm{pH}$ conditions ( 4 to 4.5 ) the amine groups are protonated $\left(\mathrm{NH}_{3}{ }^{+}\right)$and favor the extension of chitosan free chains. On the other hand, if $\mathrm{pH}$ increases near to isoelectric point, a deprotonation process could occur and lead to microaggregation by decreasing repulsion forces between particles. In the case of $\mathrm{pH}$ (4.7), amino groups of chitosan chains were further positively charged and increased electrostatic repulsion between chitosan free chains. Therefore, higher energy is needed to overcome the repulsion forces leading to formation of smaller diameter NPs.
3.3.2. Effect on $\xi$-Potential. Table 2 summarizes the influence of $\mathrm{pH}$ on physicochemical properties of thiolated chitosan nanoparticles. We observe zeta potential of samples at low $\mathrm{pH}$ from 4 to 5 which were almost constant with slight variations, except for sample at $\mathrm{pH} 5.3(30 \mathrm{mV})$ being that, at this $\mathrm{pH}$, a higher degree of deprotonation of $\left(\mathrm{NH}_{3}^{+}\right)$could happen and drop down positive charges by neutralization process resulting in unstable particles and aggregation phenomenon.

3.3.3. Effect on Morphology. Morphology of thiolated chitosan NPS at different conditions of $\mathrm{pH}(4,4.3,4.5,4.7$, 5, and 5.3) was determined by Atomic Force Microscopy. In Figure 8, we observe the morphological evolution of nanoparticles prepared from thiolated chitosan. Figure 8(a) shows particles at $\mathrm{pH} 4$; the image exhibits small and monodisperse particles with size from $150 \mathrm{~nm}$ to $160 \mathrm{~nm}$ (Figure 9). The shape consists of semispherical arrangements caused by well dilution of chitosan chains at higher hydrogen ions concentration, favoring prearrangement of protonated chitosan free chains, leading to formation of semispherical shapes and homogeneous population of NPs.

On the contrary, when $\mathrm{pH}$ was increased to 4.3 and 4.5 (Figures 8(b) and 8(c)) we observed partial microaggregates which consist of smaller particles. The size of internal particles was around $140 \mathrm{~nm}$; morphology was irregular. Decrease in particle homogeneity suggests the influence of concentration of hydrogen ions on protonation degree of chitosan amine. In addition, it is interesting that the evolution of microaggregates at $\mathrm{pH} 4.3$ more packed structure and $\mathrm{pH}$ 4.5 particles are further apart; this is attributed to the decrease of ionic strength limiting size of micro-aggregates at highest hydrogen ion concentration.

AFM images of NPs at pH 4.7 and 5 are illustrated in Figures $8(\mathrm{~d})$ and $8(\mathrm{e})$; increasing further $\mathrm{pH}$ condition leads to both formation of smaller particles supported by 


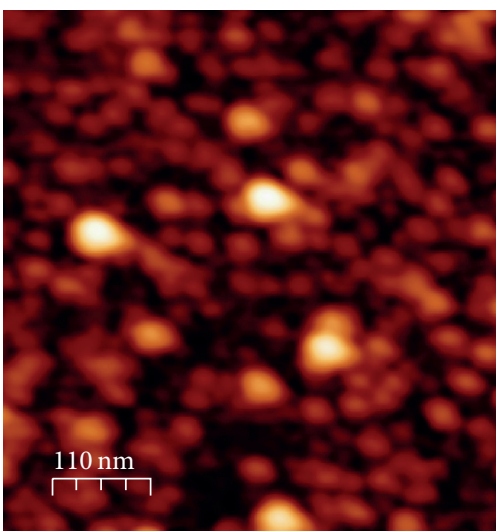

$\mathrm{NPT}_{1}$

(a)

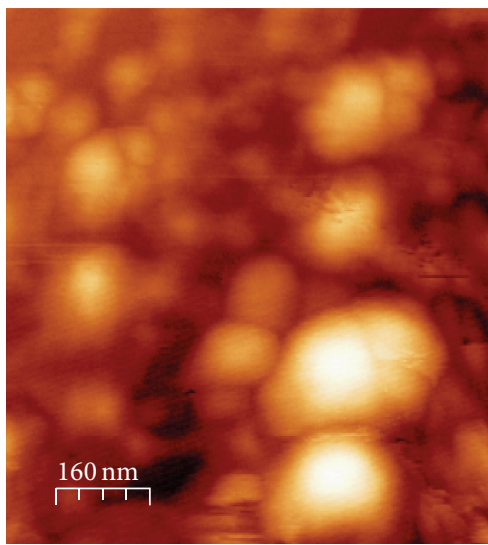

$\mathrm{NPT}_{4}$

(d)

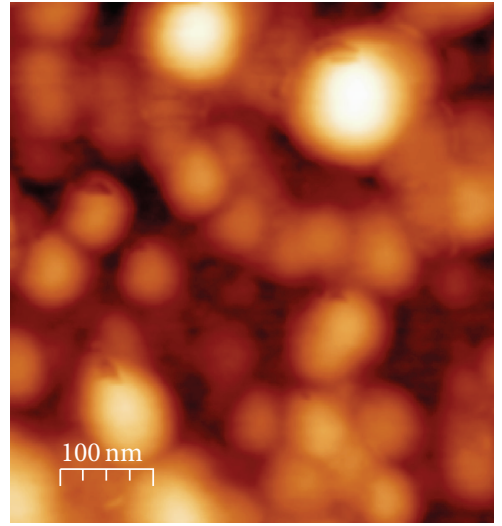

$\mathrm{NPT}_{2}$

(b)

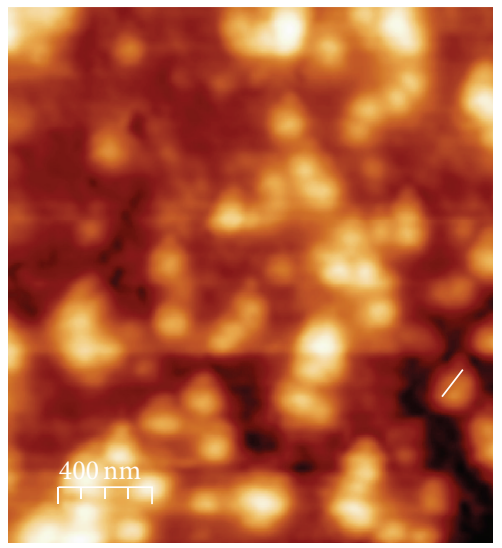

$\mathrm{NPT}_{5}$

(e)

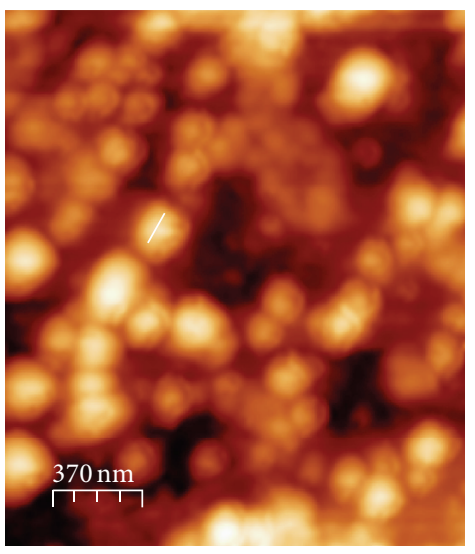

$\mathrm{NPT}_{7}$

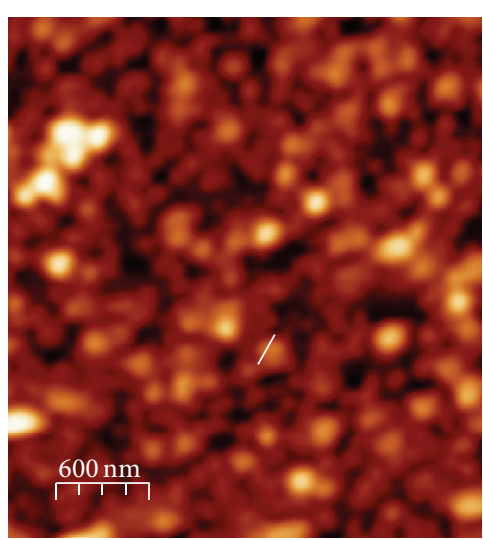

$\mathrm{NPT}_{3}$

(c)

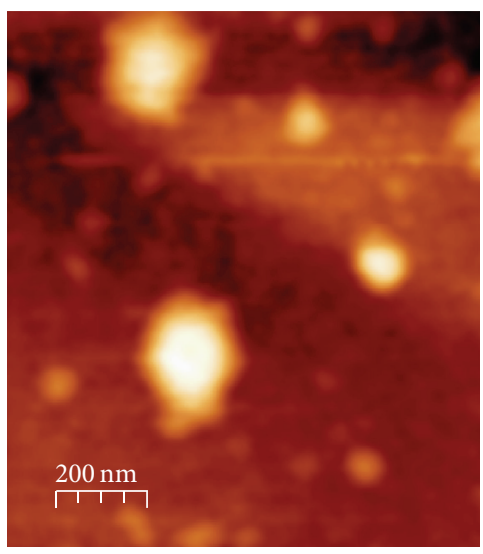

$\mathrm{NPT}_{6}$

(f)

(g)

FIGURE 5: AFM of shape evolution of thiolated chitosan nanoparticles NPT 1 (1:114), $\mathrm{NPT}_{2}(1: 106), \mathrm{NPT}_{3}(1: 100), \mathrm{NPT}_{4}(1: 94), \mathrm{NPT}_{5}(1: 86)$, $\mathrm{NPT}_{6}(1: 77)$, and NPT 7 (1:71).

higher homogeneity and more compacted structure. At this stage, stability of the particles depends on the repulsion forces, each particle which is related to ionic strength of the environment. In these cases, an important amount of positive charges of chitosan still present in the beginning stage of aggregation will favor formation of semispherical arrangement with smaller size ( $160 \mathrm{~nm}$ to $180 \mathrm{~nm})$.

AFM suggest that nanoparticles are formed at $\mathrm{pH}$ over 4.7 to 5 favoring the electrostatic and conformational process. Physicochemical properties confirm appropriate particle size, 


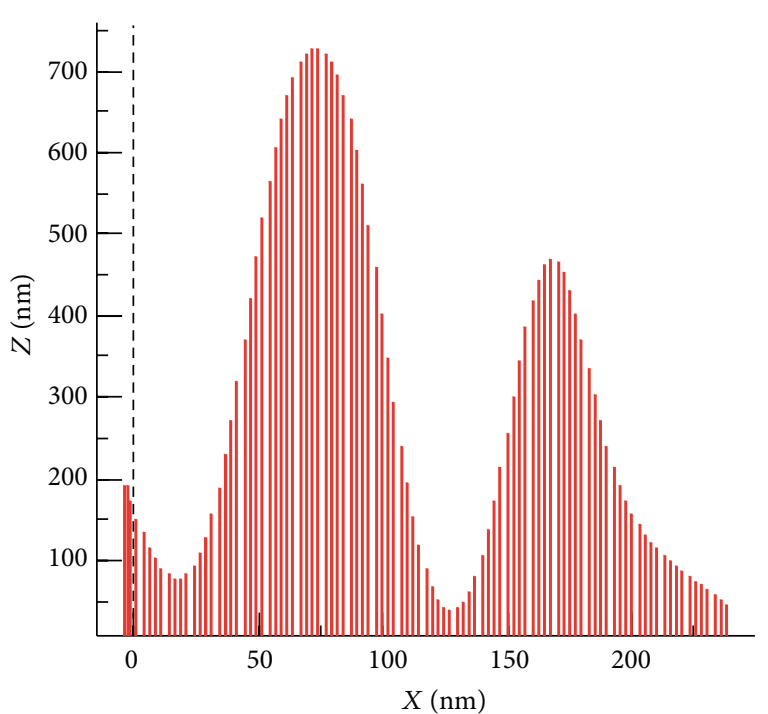

(a)

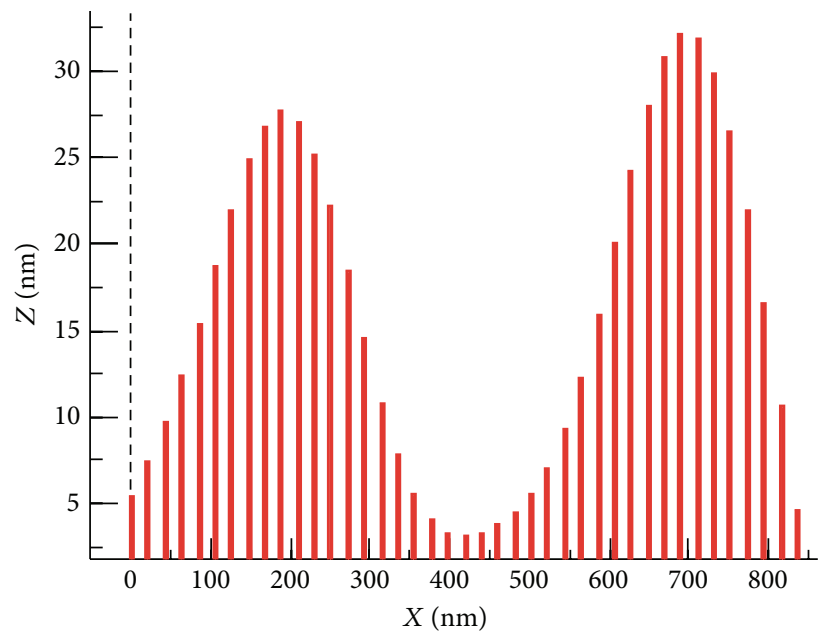

(c)

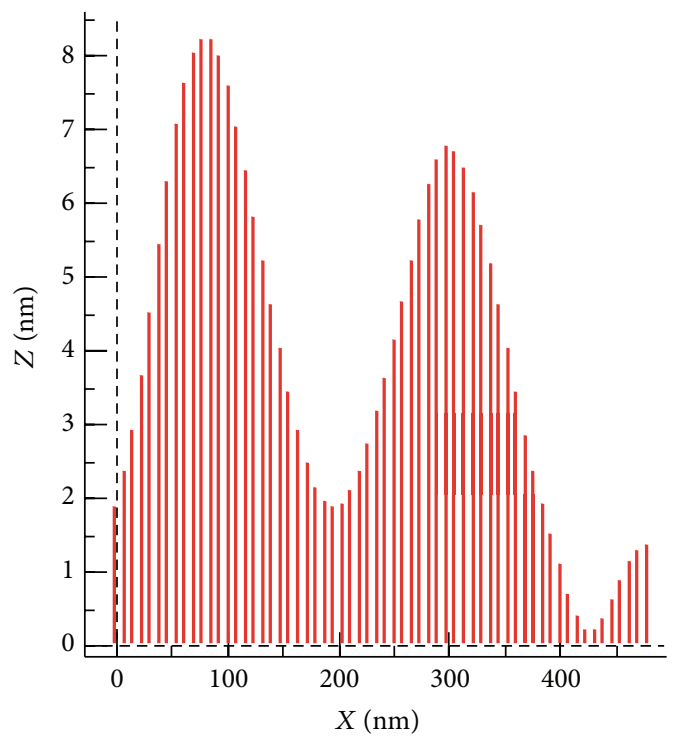

(e)

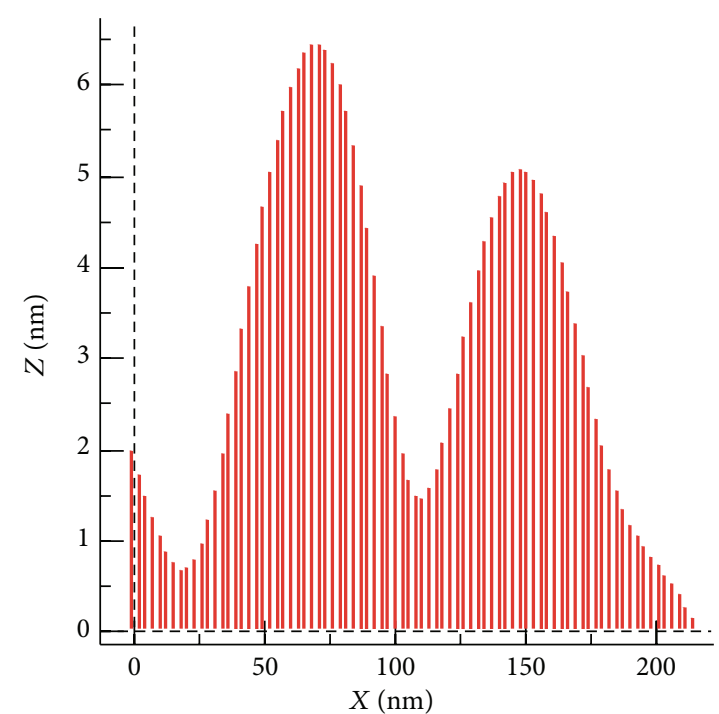

(b)

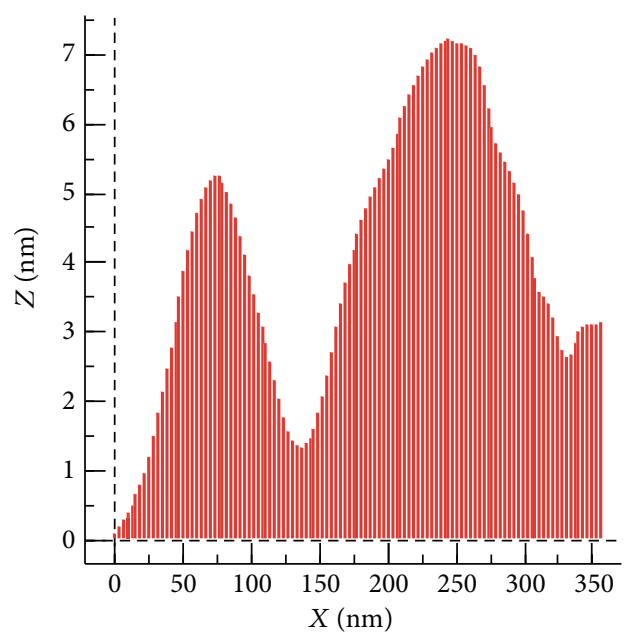

(d)

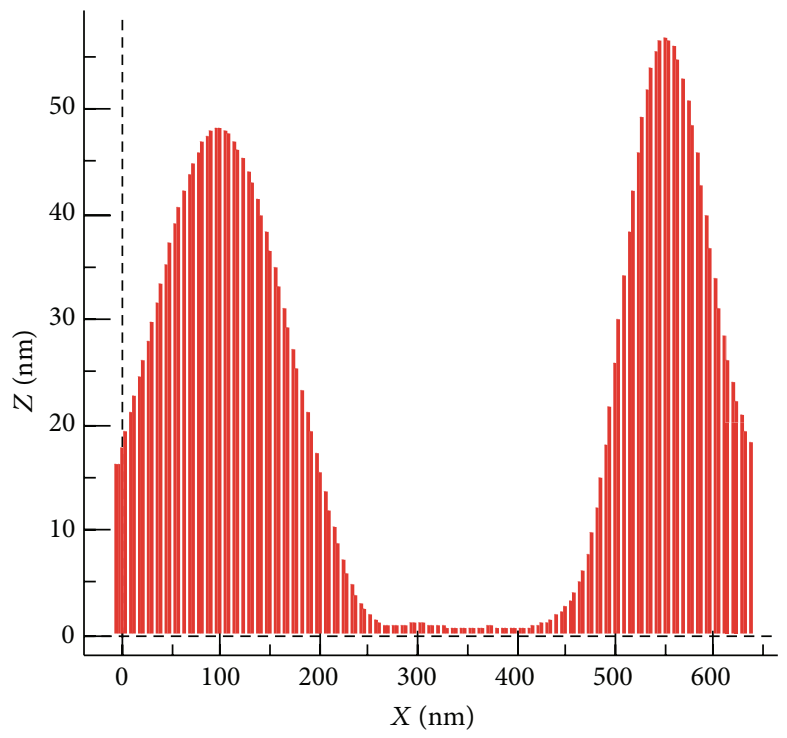

(f)

Figure 6: Continued. 


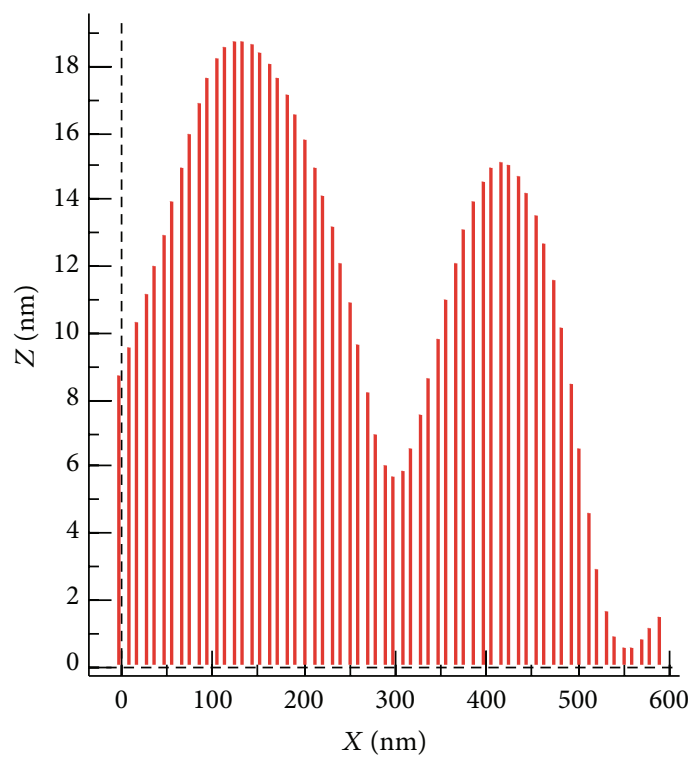

(g)

FIgURE 6: Profile curve of thiolated chitosan nanoparticles NPT 1 (1:114), $\mathrm{NPT}_{2}$ (1:106), $\mathrm{NPT}_{3}(1: 100), \mathrm{NPT}_{4}(1: 94), \mathrm{NPT}_{5}(1: 86), \mathrm{NPT}_{6}$ $(1: 77)$, and $\mathrm{NPT}_{7}(1: 71)$

TABLE 3: Thermodynamic profile of thiolated and native chitosan.

\begin{tabular}{lccccc}
\hline Sample & Gibbs energy $(\Delta G)$ & Enthalpy $(\Delta H)$ & Binding $\left(K_{a}\right)$ & \multicolumn{2}{c}{ Entropy $(\Delta S)$} \\
cal $* \mathrm{~K}^{-1} * \mathrm{~mol}^{-1}$ & $\begin{array}{c}N(\text { active sites }) \\
\text { Sites }\end{array}$ \\
\hline Native Ch (Phase 1) & -8621.78 & -7843 & $2.11 \times 10^{6}$ & 2.64 & $\mathbf{2 0}$ \\
Native Ch (Phase 2) & -8527 & $1.70 \times 10^{4}$ & $1.8 \times 10^{6}$ & 88.7 & 7.41 \\
Thiolated Ch (Phase 1) & -8938 & -6750 & $3.6 \times 10^{6}$ & 35 & $\mathbf{1 3}$ \\
Thiolated Ch (Phase 2) & -8852 & $1.79 \times 10^{4}$ & $3.11 \times 10^{6}$ & $\mathbf{2 3}$ \\
\hline
\end{tabular}

$\Delta G$ Gibbs free energy, $\Delta H$ enthalpy change, and $\Delta S$ entropy.

high stability, and appropriate morphology for potentially application as for drug delivery system for target therapy.

3.4. Calorimetric Analysis of Ch-SH/TPP Binding. Nanoparticles formation of thiolated chitosan promoted by the crosslinking of TPP was researched using isothermal titration calorimetry (ITC). This technique allows determination of the mechanism of the interaction in biomolecular process. Aiming to understand the interactions Ch-SH-TPP, we analyzed data by fitting in a mathematical model of the optimized conditions, Ch-SH/TPP 1:106 and $\mathrm{pH}=4.7$ $\left(\mathrm{NPT}_{2}\right)$. According to data analyzed of Ch-SH-TPP and ChTPP, the process of nanoparticle formation by TPP crosslinking can be adjusted to an aggregation process developed in two stages, assuming that chitosan macromolecules show single binding site. For noncooperative model with single binding site, enthalpy usually keeps constant below saturation point [35, 41]. Figure 10 describes the evolution of $\mathrm{Ch}$ TPP and Ch-SH-TPP nanoparticle formation and Table 3 shows $\Delta H, \Delta S$, and $\Delta G$ corresponding values. The first stage is characterized by an exothermic process, while the second stage is entropic process; however, both processes were spontaneous. The exothermic process is developed by electrostatic interactions between TPP molecules with amine groups of Ch-TPP and Ch-SH-TPP chains. This electrostatic association allows expanded arrangements of macromolecule chains as the TPP molecules are attached to Ch-TPP or Ch$\mathrm{SH}-\mathrm{TPP}$ by attractive effect.

At this first stage, once amine groups in the Ch-TPP and $\mathrm{Ch}-\mathrm{SH}-\mathrm{TPP}$ are saturated by the anionic linker, chitosan molecules adopt a structural conformation that allow the formation of nanoparticles. This phenomenon occurs at the end of the first stage; this stage is favored by enthalpy. According to the mechanism involved in the evolution of cross-linking process to native chitosan-TPP (Figure 11) and thiolated chitosan-TPP, we observed exothermic increment below the initial amounts of TPP; these changes can be interpreted as the first process binding. In the case of thiolated chitosan/TPP interaction, Figure 10 highlights exothermic changes at low concentration of TPP, which can be associated with initial conformational arrangements of chitosan free chains in solution from semicoil state to extended conformation. This mechanism allows the later attachment of TPP molecules by ionic interaction between positive charges of chitosan and negative from TPP. 

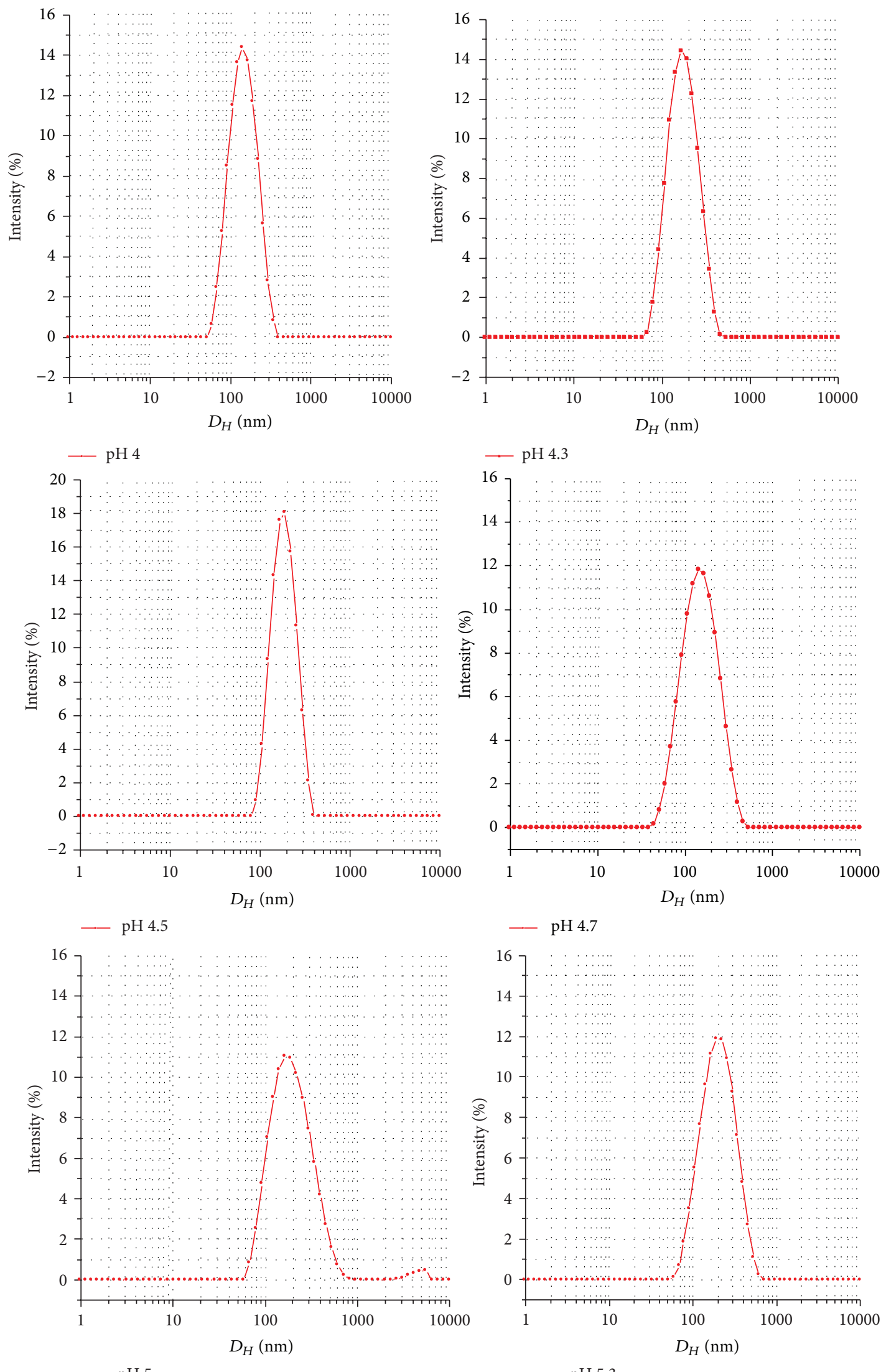

$\longrightarrow$ pH 5

pH 5.3

FIGURE 7: Particle size distribution of chitosan SH/TPP nanoparticles prepared at pH 4, 4.3, 4.5, 4.7, 5, and 5.3. 


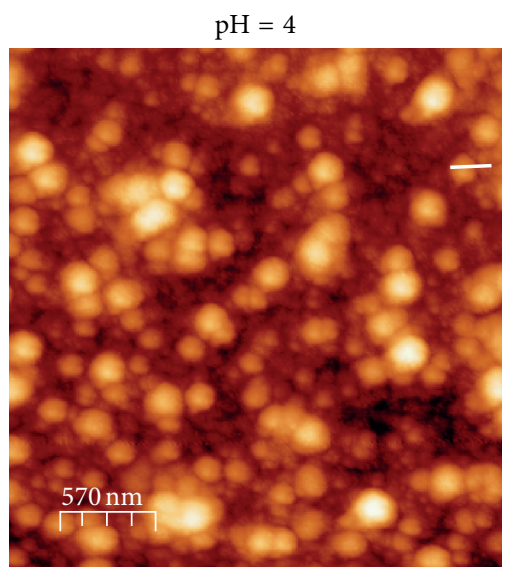

(a)

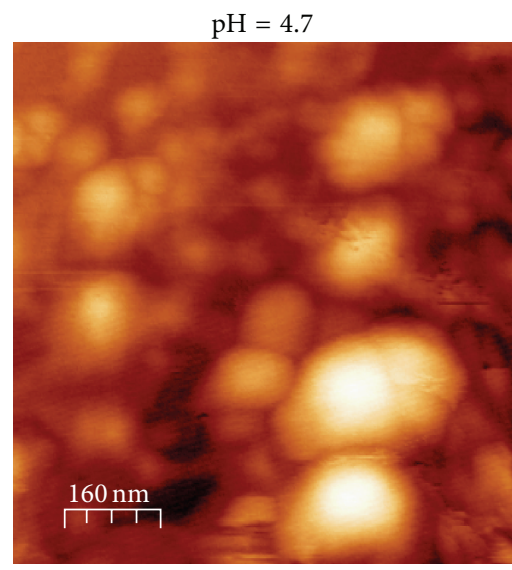

(d)

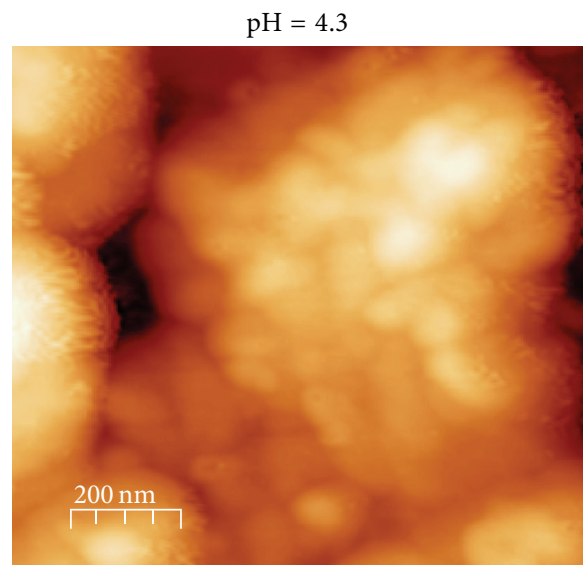

(b)

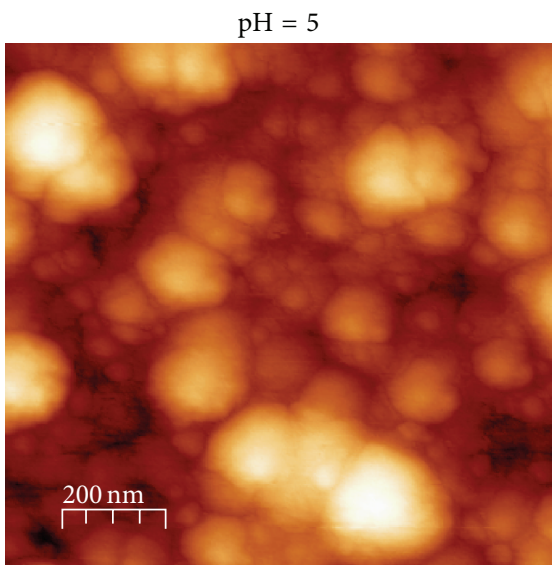

(e)

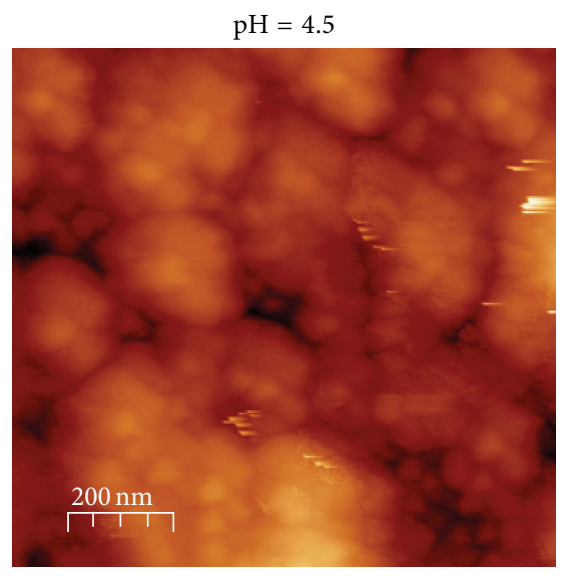

(c)

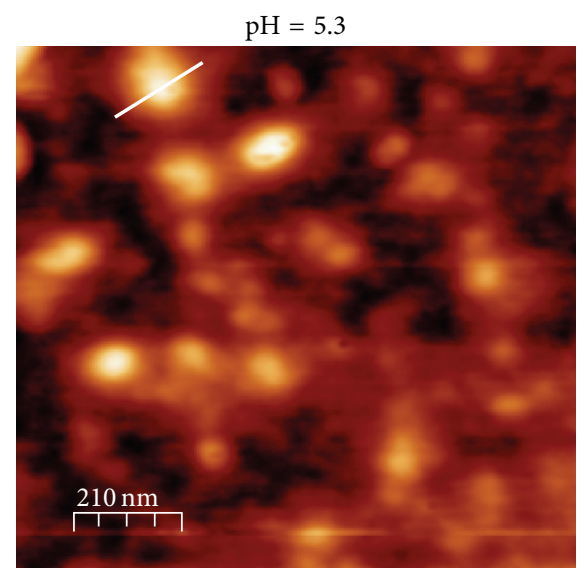

(f)

FIGURE 8: AFM of morphology evolution of thiolated chitosan nanoparticles.

According to thermodynamics of the first phase, the structural arrangement of thiolated chitosan chains occurs as a spontaneous process $(\Delta G=-8938 \mathrm{cal} / \mathrm{mol})$; the equilibrium favors the expanded conformation of chitosan chains, probably favored by the concentration of ligand and the temperature of the initial solution. In a direct comparison between thiolated and unmodified chitosan, Gibbs free energy reflects a higher stability in the case of thiolated chitosan by a quantitative difference of $317 \mathrm{cal} * \mathrm{~mol}$. This change indicates a highest stability caused by interaction of disulfide bonds. On the other hand, ITC results indicate an increment of entropy change $(\Delta S),\left(7.41 \mathrm{cal} * \mathrm{~K}^{-1} * \mathrm{~mol}^{-1} \mathrm{Ch}-\right.$ SH-TPP), and $\left(2.64 \mathrm{cal} * \mathrm{~K}^{-1} * \mathrm{~mol}^{-1} \mathrm{Ch}\right.$-TPP); this means that modified chitosan is entropic driven by a molecular prearrangement of chitosan and TPP molecules.

The second phase involves an endothermic mechanism. Equilibrium is favored by the linkage formation of extended chitosan occupied by TPP molecules. Additionally, the graph shows an increment of endothermic signal at the second phase, possibly due to an entropic phenomenon. This phenomenon at the second stage was initiated when chitosan active sites were occupied by TPP molecules; after that, ionic forces led to intermolecular interaction between chitosan chains. Before nanoparticles formation, water molecules are linked to backbone of chitosan chains by hydrogen bonds, the rupture of these hydrogen bonds causes energy absorption and starting the endothermic route. Entropy increment $(\Delta S)$ $\left(88.7 \mathrm{cal} * \mathrm{~K}^{-1} * \mathrm{~mol}^{-1} \mathrm{Ch}-\mathrm{TPP}\right)$ and $(\Delta S)\left(86 \mathrm{cal} * \mathrm{~K}^{-1} * \mathrm{~mol}^{-1}\right.$ Ch-SH-TPP) involves a spontaneous structural conformation of chitosan chain. Gibbs free energy is related with the endothermic signal at higher amount of TPP, we describe this second step as a spontaneous process (Gibbs free energy $-8852 \mathrm{cal} * \mathrm{~mol})$, and this value suggests that the reaction favors Ch-SH-TPP cross-linking process.

Bernkop-Schnürch et al. [29] reported stability enhancement of nanoparticles; they prepared micro and nanoparticles of native chitosan/tripolyphosphate. The results of ITC shows enthalpy changes at binding process $(\Delta H=$ $6000 \mathrm{cal} / \mathrm{mol}$ ). The cooperative model was adjusted.

The comparative ITC analysis between native and thiolated chitosan is shown in Figure 12. Addition of mercapto chains reveals significant contributions of thiol groups in thermodynamic profile. The magnitude $N$ [43] (Table 3) exposes the abrupt decrease of the total number of active sites; we associate this important decrease of $N$ with the partial substitution in protonated amine group $\left(\mathrm{NH}_{3}{ }^{+}\right)$. 


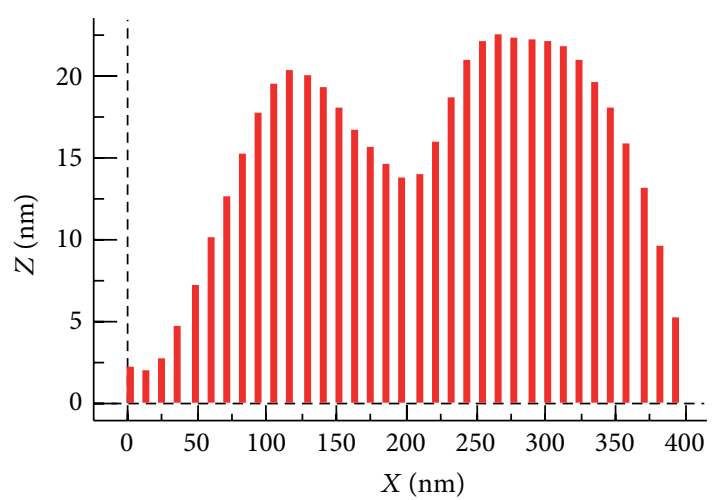

(a)

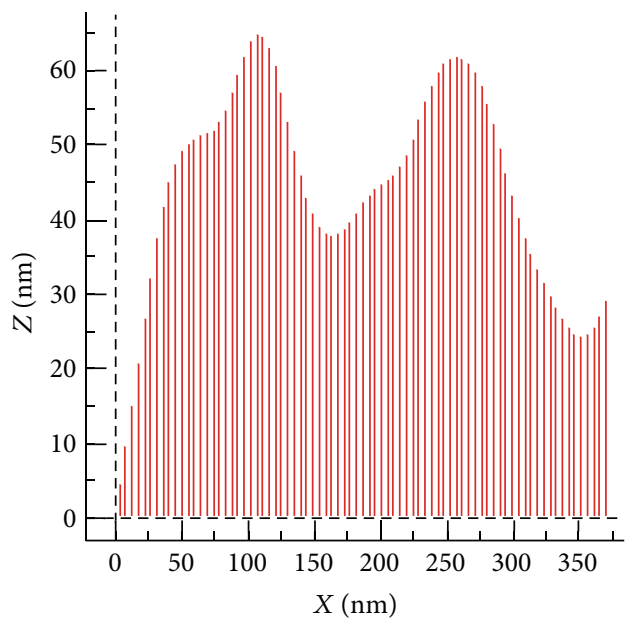

(c)

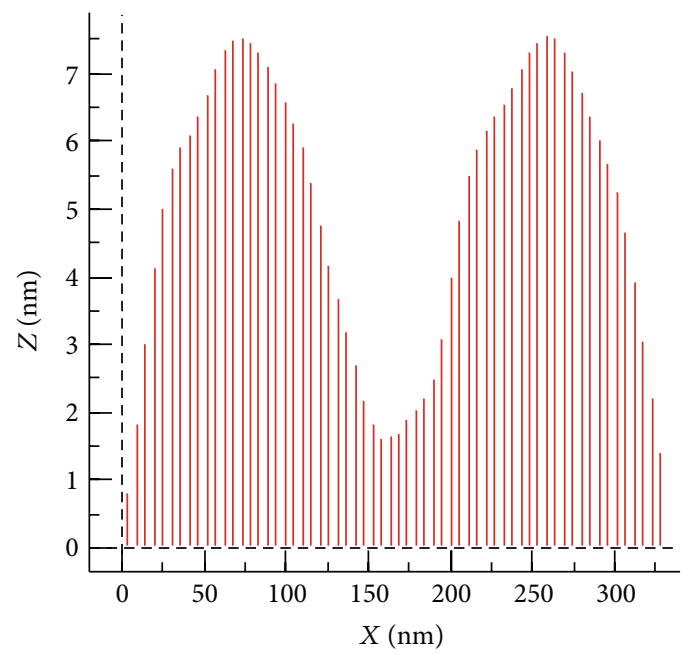

(e)

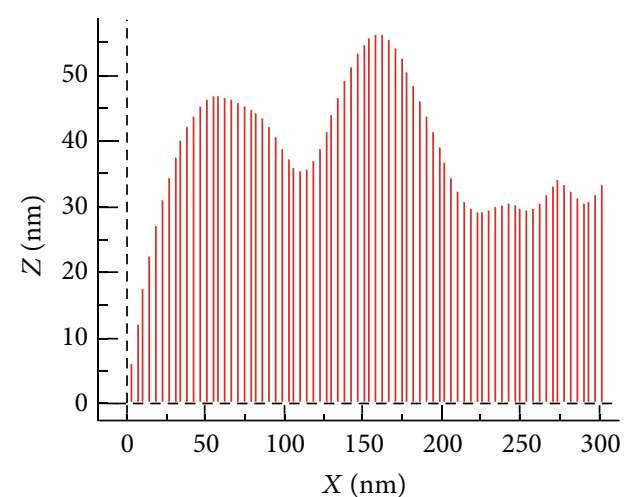

(b)

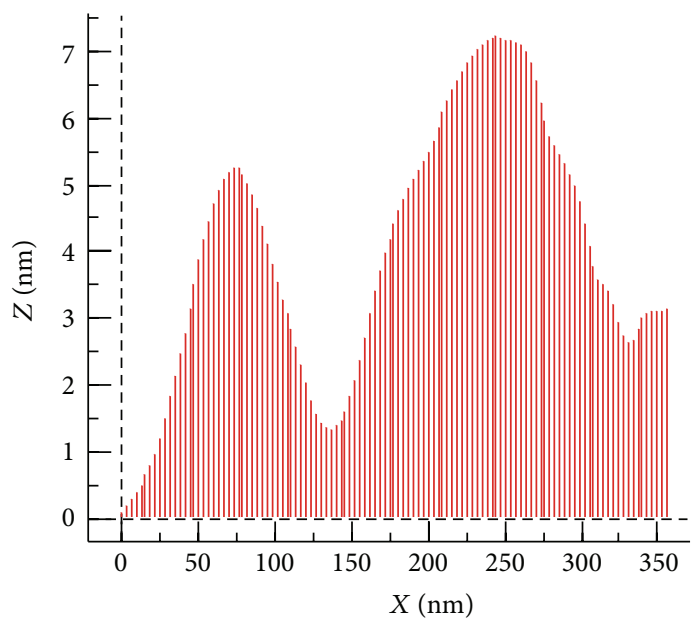

(d)

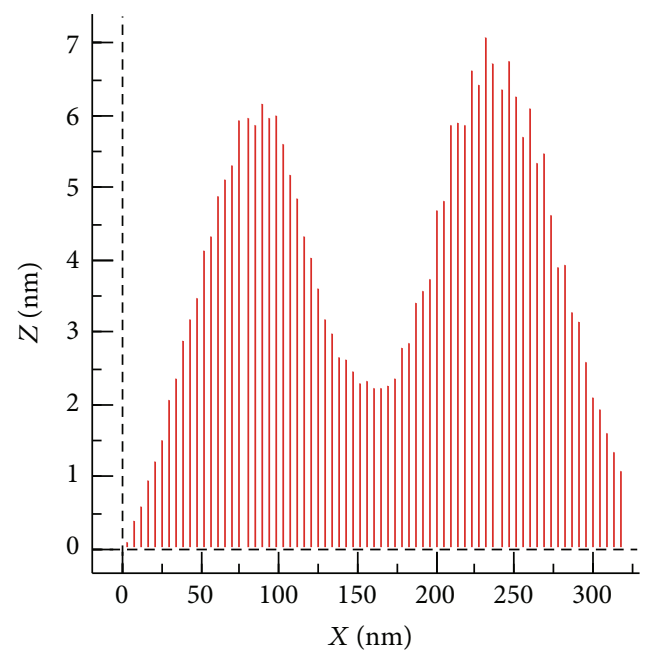

(f)

FIGURE 9: Profile curve of thiolated chitosan nanoparticles of Ch-SH/TPP nanoparticles prepared at pH 4, 4.3, 4.5, 4.7, 5, and 5.3.

Despite important changes in the number of active sites in thiolated chitosan, the values of binding constant $\left(K_{a}\right)$ were similar with native chitosan. Apparently, both reactions follow the two-phase mechanism divided at first in structural arrangement of chitosan chains, from semicoil state to expanded structure $\left(\Delta G_{\text {NativeCh }}=-8621.78 \mathrm{cal} * \mathrm{~mol}\right.$
$\left.\Delta G_{\text {ThiolatedCh }}=-8938 \mathrm{cal} * \mathrm{~mol}\right)$. Gibbs free energy confirms a similar spontaneous mechanism favored to keep expanded arrangement. Additionally, in the second stage, an important increment of endothermic peak was observed after equivalent point. This energy change is due to structural reorganization of chitosan free chains, favoring semispherical shape 

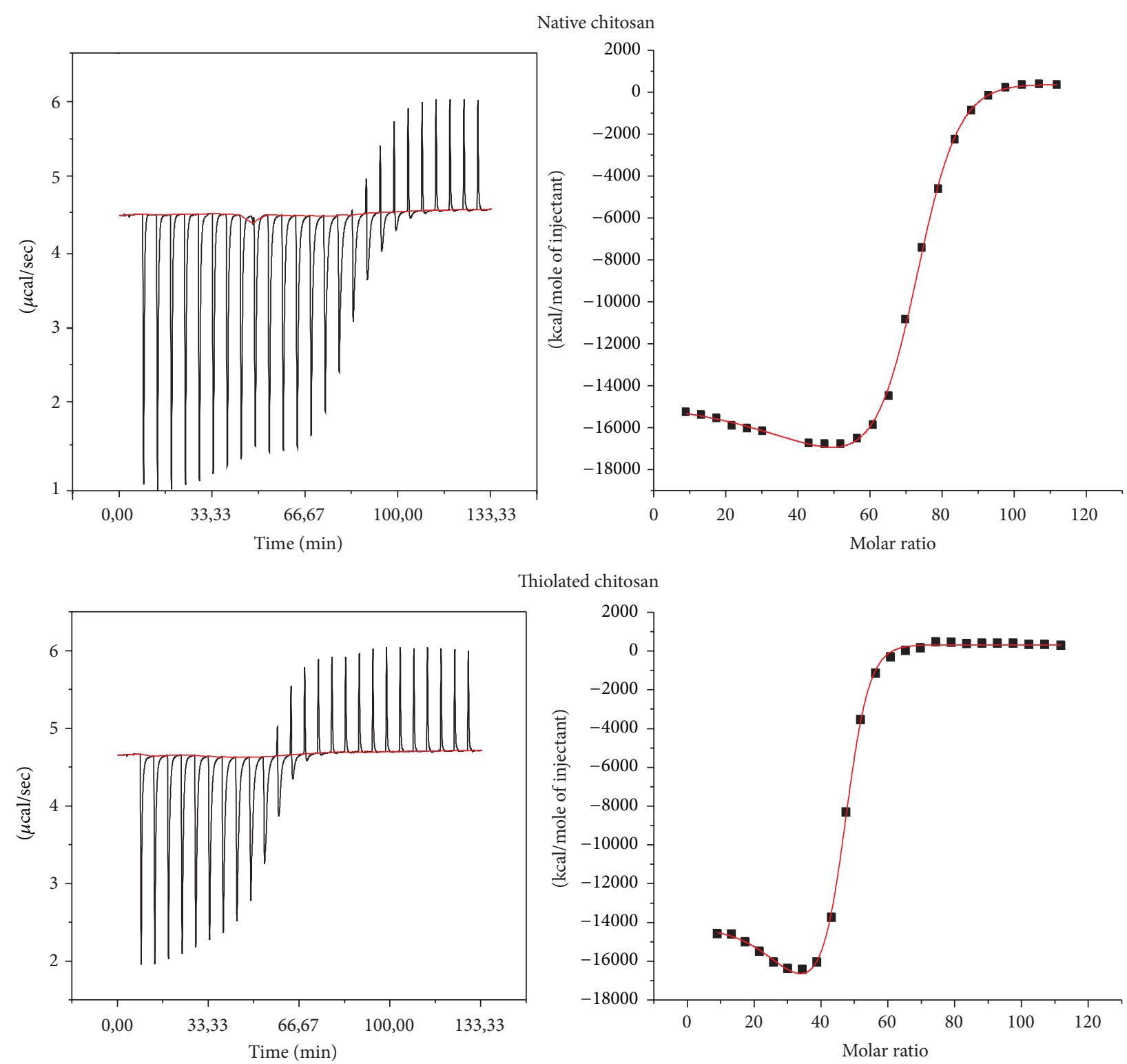

FIgURE 10: ITC and raw data of thiolated chitosan.

of nanoparticles. A positive value of entropy $\left(\Delta S_{\text {NativeCh }}=\right.$ $\left.88.7 \mathrm{cal} * \mathrm{~K}^{-1} * \mathrm{~mol}^{-1} \Delta S_{\text {ThiolatedCh }}=86 \mathrm{cal} * \mathrm{~K}^{-1} * \mathrm{~mol}^{-1}\right)$ suggests that water molecules are expelled from inside of chitosan and that formation of nanoparticles may happen after the saturation point [21].

\section{Conclusions}

In this work, we researched the effect of chemical derivatization on native chitosan properties by coupling reaction with 3-mercaptopropionic acid; the reaction reached $11 \%$ of modification degree of free amine groups. Chitosan derivatized with thiol groups allows preparation of stable, semispherical, and not aggregated nanoparticles, even at a high concentration of TPP. The morphologic evolution of the NPs as a function of $\mathrm{pH}$ solution was evaluated by AFM images, where a monodisperse population of nanoparticles and well defined semispheric structures were observed at $\mathrm{pH}$ 4.7. Also, a strong dependency of molar ratio (Ch-SH/TPP) with hydrodynamic size and surface charge of chitosan nanoparticles were found. In this manner, physicochemical properties of these new nanoparticles could be modulated in size and charge, between $100 \mathrm{~nm}$ to $200 \mathrm{~nm}$, and $30 \mathrm{mV}$ and $40 \mathrm{mV}$, respectively. On the other hand, a thermodynamic profile was carried out by ITC in order to understand the formation mechanism of nanoparticles. The reduction of magnitude $(N)$ is related with the degree of substitution in amine groups. This difference could explain the variations of stability between thiolated and unmodified chitosan. We analyzed the nanoparticles formation assuming the existence of one binding site model and the aggregation process 


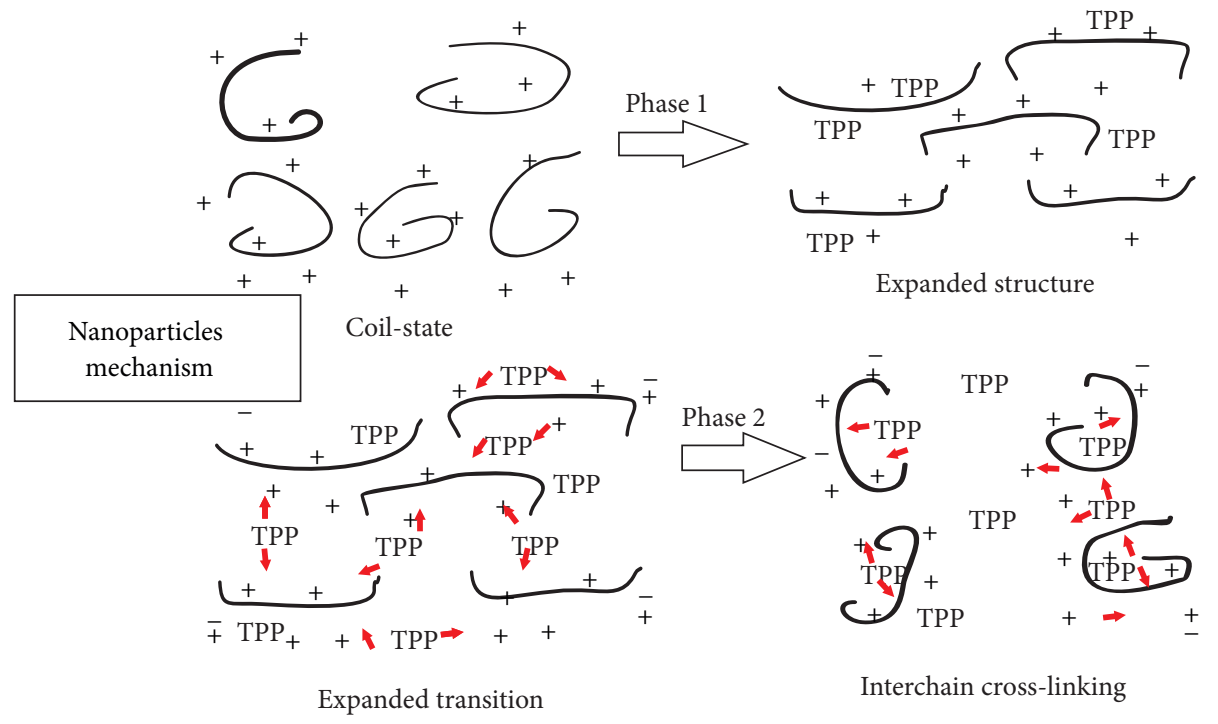

FIgURE 11: Two-phase mechanism of nanoparticles formation.

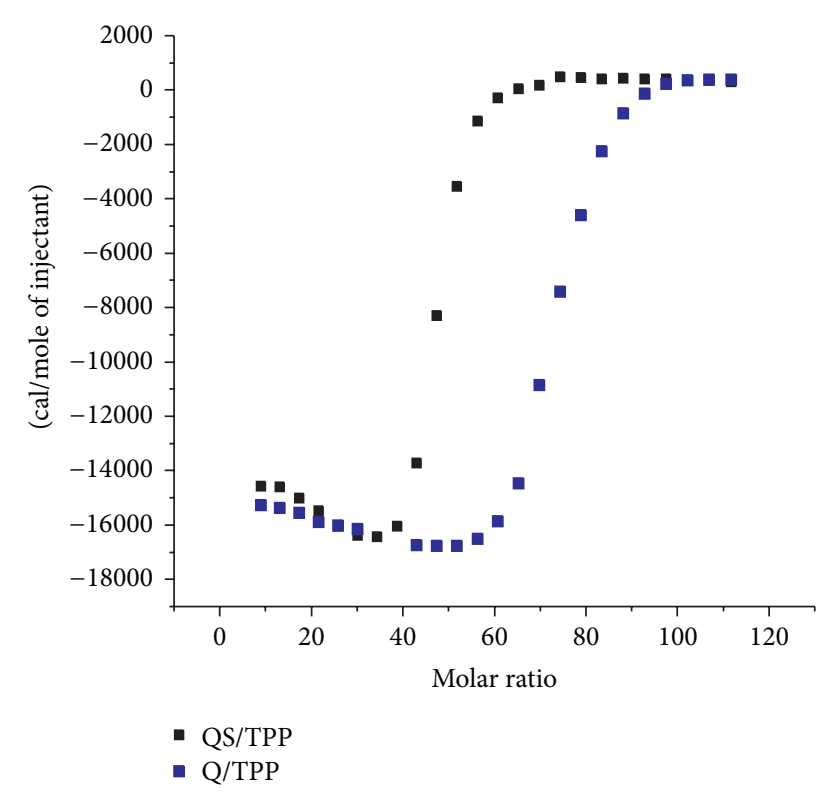

FIGURE 12: ITC comparative between native chitosan and thiolated chitosan.

in two stages. Firstly, we observed an exothermic process associated with conformational changes of free chitosan and thiolated chitosan chains promoted by TPP molecules. The second phase involves interchain interactions characterized by an endothermic mechanism. Additionally, according to the thermodynamic profile (Gibbs free energy and binding constant) the final cross-linking process is favored to achieve semispherical shapes nanoparticles.

\section{Conflict of Interests}

The authors declare that there is no conflict of interests regarding the publication of this paper.

\section{Acknowledgments}

Miguel A. Valdez acknowledges the financial support for this research (CONACYT, México, and Project no. CB-201001-151794), Josué Juárez thanks CONACYT, México, and Project no. CB-2014-01-236185, Reynaldo Esquivel acknowledges CONACYT, México, for Cátedra CONACYT support (Projects 2264 and RN 2264).

\section{References}

[1] X. Wang, C. J. Summers, and Z. L. Wang, "Large-scale hexagonal-patterned growth of aligned $\mathrm{ZnO}$ nanorods for nano-optoelectronics and nanosensor arrays," Nano Letters, vol. 4, no. 3, pp. 423-426, 2004.

[2] Q. Zhang and K. T. Chuang, "Adsorption of organic pollutants from effluents of a Kraft pulp mill on activated carbon and polymer resin," Advances in Environmental Research, vol. 5, no. 3, pp. 251-258, 2001.

[3] F. Lai, S. A. Wissing, R. H. Müller, and A. M. Fadda, “Artemisia arborescens L essential oil-loaded solid lipid nanoparticles for potential agricultural application: preparation and characterization," AAPS PharmSciTech, vol. 7, no. 1, pp. E10-E18, 2006.

[4] H. Ragelle, R. Riva, G. Vandermeulen et al., "Chitosan nanoparticles for siRNA delivery: optimizing formulation to increase stability and efficiency," Journal of Controlled Release, vol. 176, no. 1, pp. 54-63, 2014.

[5] S. Sundar, J. Kundu, and S. C. Kundu, "Topical review: biopolymeric nanoparticles," Science and Technology of Advanced Materials, vol. 11, no. 1, Article ID 014104, 13 pages, 2010.

[6] J. P. Rao and K. E. Geckeler, "Polymer nanoparticles: preparation techniques and size-control parameters," Progress in Polymer Science, vol. 36, no. 7, pp. 887-913, 2011.

[7] A. Kumari, S. K. Yadav, and S. C. Yadav, "Biodegradable polymeric nanoparticles based drug delivery systems," Colloids and Surfaces B: Biointerfaces, vol. 75, no. 1, pp. 1-18, 2010.

[8] S. K. Nitta and K. Numata, "Biopolymer-based nanoparticles for drug/gene delivery and tissue engineering," International Journal of Molecular Sciences, vol. 14, no. 1, pp. 1629-1654, 2013. 
[9] L. Cismaru and M. Popa, "Polymeric nanoparticles with biomedical applications," Revue Roumaine de Chimie, vol. 55, no. 8, pp. 433-442, 2010.

[10] J. L. Perry, K. G. Reuter, M. P. Kai et al., "PEGylated PRINT nanoparticles: the impact of PEG density on protein binding, macrophage association, biodistribution, and pharmacokinetics," Nano Letters, vol. 12, no. 10, pp. 5304-5310, 2012.

[11] A. Rampino, M. Borgogna, P. Blasi, B. Bellich, and A. Cesàro, "Chitosan nanoparticles: preparation, size evolution and stability," International Journal of Pharmaceutics, vol. 455, no. 1-2, pp. 219-228, 2013.

[12] F. Danhier, E. Ansorena, J. M. Silva, R. Coco, A. Le Breton, and V. Préat, "PLGA-based nanoparticles: an overview of biomedical applications," Journal of Controlled Release, vol. 161, no. 2, pp. 505-522, 2012.

[13] B. Mohamed and R. Entsar, "A Biopolymer chitosan and its derivatives as promising antimicrobial agents against plant pathogens and their applications in crop protection," International Journal of Carbohydrate Chemistry, vol. 2011, Article ID 460381, 29 pages, 2011.

[14] S. Chawla and S. Kanatt, "Chitosan," in Polysaccharides, pp. 124, Springer, 2014.

[15] G. S. Dhillon, S. Kaur, S. J. Sarma, S. K. Brar, M. Verma, and R. Y. Surampalli, "Recent development in applications of important biopolymer chitosan in biomedicine, pharmaceuticals and personal care products," Current Tissue Engineering, vol. 2, no. 1, pp. 20-40, 2013.

[16] P. Calvo, C. Remuñán-López, J. L. Vila-Jato, and M. J. Alonso, "Novel hydrophilic chitosan-polyethylene oxide nanoparticles as protein carriers," Journal of Applied Polymer Science, vol. 63, no. 1, pp. 125-132, 1997.

[17] W. Fan, W. Yan, Z. Xu, and H. Ni, "Formation mechanism of monodisperse, low molecular weight chitosan nanoparticles by ionic gelation technique," Colloids and Surfaces B: Biointerfaces, vol. 90, no. 1, pp. 21-27, 2012.

[18] P. K. Dutta, J. Duta, and V. S. Tripathi, "Chitin and chitosan: chemistry, properties and applications," Journal of Scientific and Industrial Research, vol. 63, no. 1, pp. 20-31, 2004.

[19] E. Robles, E. Villar, M. Alatorre-Meda et al., "Effects of the hydrophobization on chitosan-insulin nanoparticles obtained by an alkylation reaction on chitosan," Journal of Applied Polymer Science, vol. 129, no. 2, pp. 822-834, 2013.

[20] V. K. Mourya and N. N. Inamdar, "Chitosan-modifications and applications: opportunities galore," Reactive \& Functional Polymers, vol. 68, no. 6, pp. 1013-1051, 2008.

[21] R. Emmanuel, J. Josué, T. Pablo, M. Víctor, and V. Miguel, "Properties of insulin-chitosan complexes obtained by an alkylation reaction on chitosan," Journal of Applied Polymer Science, vol. 131, no. 6, 2014.

[22] N. M. Alves and J. F. Mano, "Chitosan derivatives obtained by chemical modifications for biomedical and environmental applications," International Journal of Biological Macromolecules, vol. 43, no. 5, pp. 401-414, 2008.

[23] H. Sashiwa and S.-I. Aiba, "Chemically modified chitin and chitosan as biomaterials," Progress in Polymer Science, vol. 29, no. 9, pp. 887-908, 2004.

[24] D.-W. Lee, S. A. Shirley, R. F. Lockey, and S. S. Mohapatra, "Thiolated chitosan nanoparticles enhance anti-inflammatory effects of intranasally delivered theophylline," Respiratory Research, vol. 7, article 112, 2006.
[25] G. Millotti, C. Samberger, E. Fröhlich, D. Sakloetsakun, and A. Bernkop-Schnürch, "Chitosan-4-mercaptobenzoic acid: synthesis and characterization of a novel thiolated chitosan," Journal of Materials Chemistry, vol. 20, no. 12, pp. 2432-2440, 2010.

[26] A. Anitha, N. Deepa, K. P. Chennazhi, S. V. Nair, H. Tamura, and R. Jayakumar, "Development of mucoadhesive thiolated chitosan nanoparticles for biomedical applications," Carbohydrate Polymers, vol. 83, no. 1, pp. 66-73, 2011.

[27] W. Dhadhang, F. Achmad, and A. Ratna, "Synthesis of thiolated chitosan as matrix for the preparation of metformin hydrochloride microparticles," Research in Pharmacy, vol. 2, no. 1, pp. 2635, 2012.

[28] E.-B. Ko, H.-Y. Cho, T.-H. Kim, C.-H. Yea, and J.-W. Choi, "Cell chip with a thiolated chitosan self-assembled monolayer to detect the effects of anticancer drugs on breast normal and cancer cells," Colloids and Surfaces B: Biointerfaces, vol. 112, pp. 387-392, 2013.

[29] A. Bernkop-Schnürch, M. Hornof, and D. Guggi, “Thiolated chitosans," European Journal of Pharmaceutics and Biopharmaceutics, vol. 57, no. 1, pp. 9-17, 2004.

[30] M. Prabaharan, "Review paper: chitosan derivatives as promising materials for controlled drug delivery," Journal of Biomaterials Applications, vol. 23, no. 1, pp. 5-36, 2008.

[31] F. Atyabi, F. Talaie, and R. Dinarvand, "Thiolated chitosan nanoparticles as an oral delivery system for amikacin: in vitro and ex vivo evaluations," Journal of Nanoscience and Nanotechnology, vol. 9, no. 8, pp. 4593-4603, 2009.

[32] X. Zhu, M. Su, S. Tang et al., "Synthesis of thiolated chitosan and preparation nanoparticles with sodium alginate for ocular drug delivery," Molecular Vision, vol. 18, pp. 1973-1982, 2012.

[33] Y. Boonsongrit, B. W. Mueller, and A. Mitrevej, "Characterization of drug-chitosan interaction by ${ }^{1} \mathrm{H}$ NMR, FTIR and isothermal titration calorimetry," European Journal of Pharmaceutics and Biopharmaceutics, vol. 69, no. 1, pp. 388-395, 2008.

[34] P. Yousefpour, F. Atyabi, E. Vasheghani-Farahani, A.-A. M. Movahedi, and R. Dinarvand, "Targeted delivery of doxorubicin-utilizing chitosan nanoparticles surface-functionalized with anti-Her2 trastuzumab," International Journal of Nanomedicine, vol. 2011, article 6, pp. 1977-1990, 2011.

[35] Y. Huang and Y. Lapitsky, "Monovalent salt enhances colloidal stability during the formation of chitosan/tripolyphosphate microgels," Langmuir, vol. 27, no. 17, pp. 10392-10399, 2011.

[36] B. Han, Y. Wei, X. Jia, J. Xu, and G. Li, "Correlation of the structure, properties, and antimicrobial activity of a soluble thiolated chitosan derivative," Journal of Applied Polymer Science, vol. 125, no. 2, pp. E143-E148, 2012.

[37] E. S. de Alvarenga, "Characterization and properties of chitosan," in Biotechnology of Biopolymers, M. Elnashar, Ed., vol. 24, chapter 5, p. 364, InTech, Rijeka, Croatia, 2011.

[38] L. Vijapur and S. Sreenivas, "Thiolated chitosan a gift to mucoadhesive drug delivery system-a review," International Journal of Pharmaceutical Innovations, vol. 3, no. 4, pp. 86-95, 2013.

[39] R. Martien, B. Loretz, A. M. Sandbichler, and A. B. Schnürch, "Thiolated chitosan nanoparticles: transfection study in the Caco-2 differentiated cell culture," Nanotechnology, vol. 19, no. 4, Article ID 045101, 9 pages, 2008.

[40] M. Clara, L. Ruo, and C. Gianluca, "Chitosan nanoparticles as therapeutic protein nanocarriers: the effect of ph on particle formation and encapsulation efficiency," Polymer Composites, vol. 34, no. 9, pp. 1539-1545, 2013. 
[41] M. A. Torres, M. M. Beppu, and C. C. Santana, "Characterization of chemically modified chitosan microspheres as adsorbents using standard proteins (bovine serum albumin and lysozyme)," Brazilian Journal of Chemical Engineering, vol. 24, no. 3, pp. 325-336, 2007.

[42] X.-F. Li, X.-Q. Feng, S. Yang, T.-P. Wang, and Z.-X. Su, "Effects of molecular weight and concentration of chitosan on antifungal activity against aspergillus niger," Iranian Polymer Journal, vol. 17, no. 11, pp. 843-852, 2008.

[43] E. Lee, J. Lee, and S. Jon, "A novel approach to oral delivery of insulin by conjugating with low molecular weight chitosan," Bioconjugate Chemistry, vol. 21, no. 10, pp. 1720-1723, 2010. 

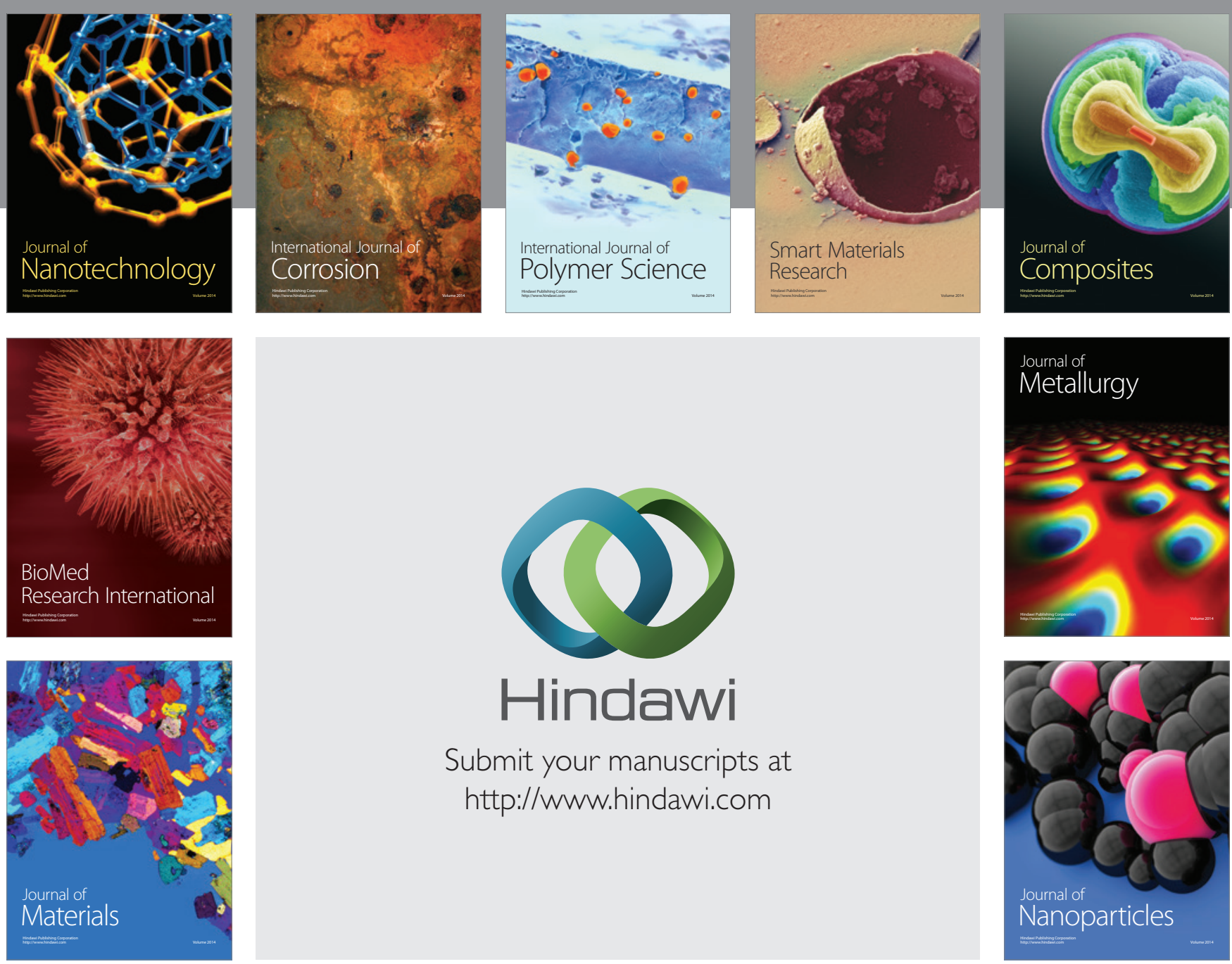

Submit your manuscripts at http://www.hindawi.com
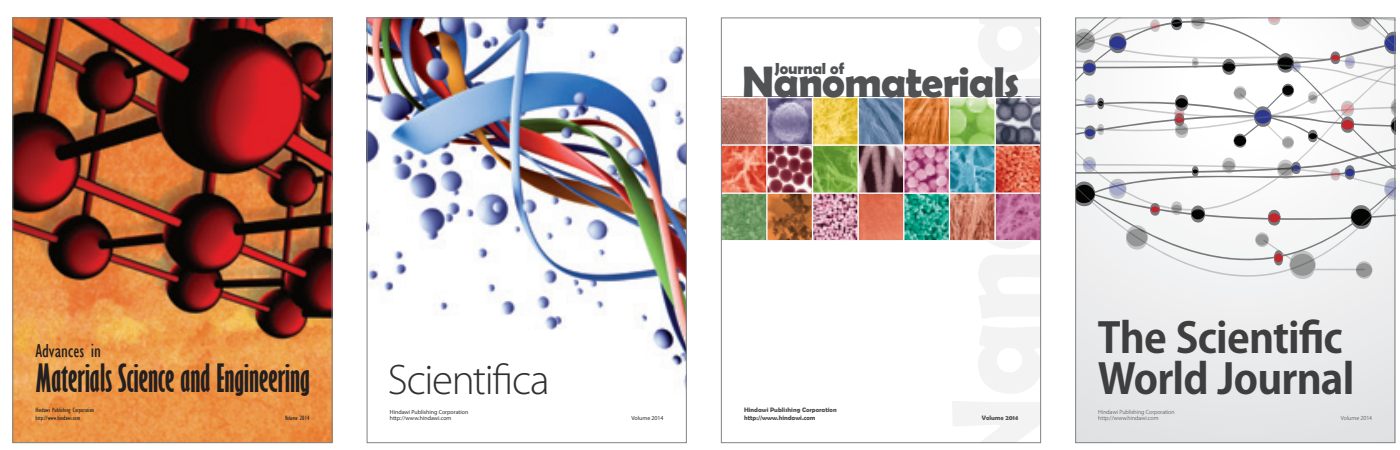

\section{The Scientific World Journal}
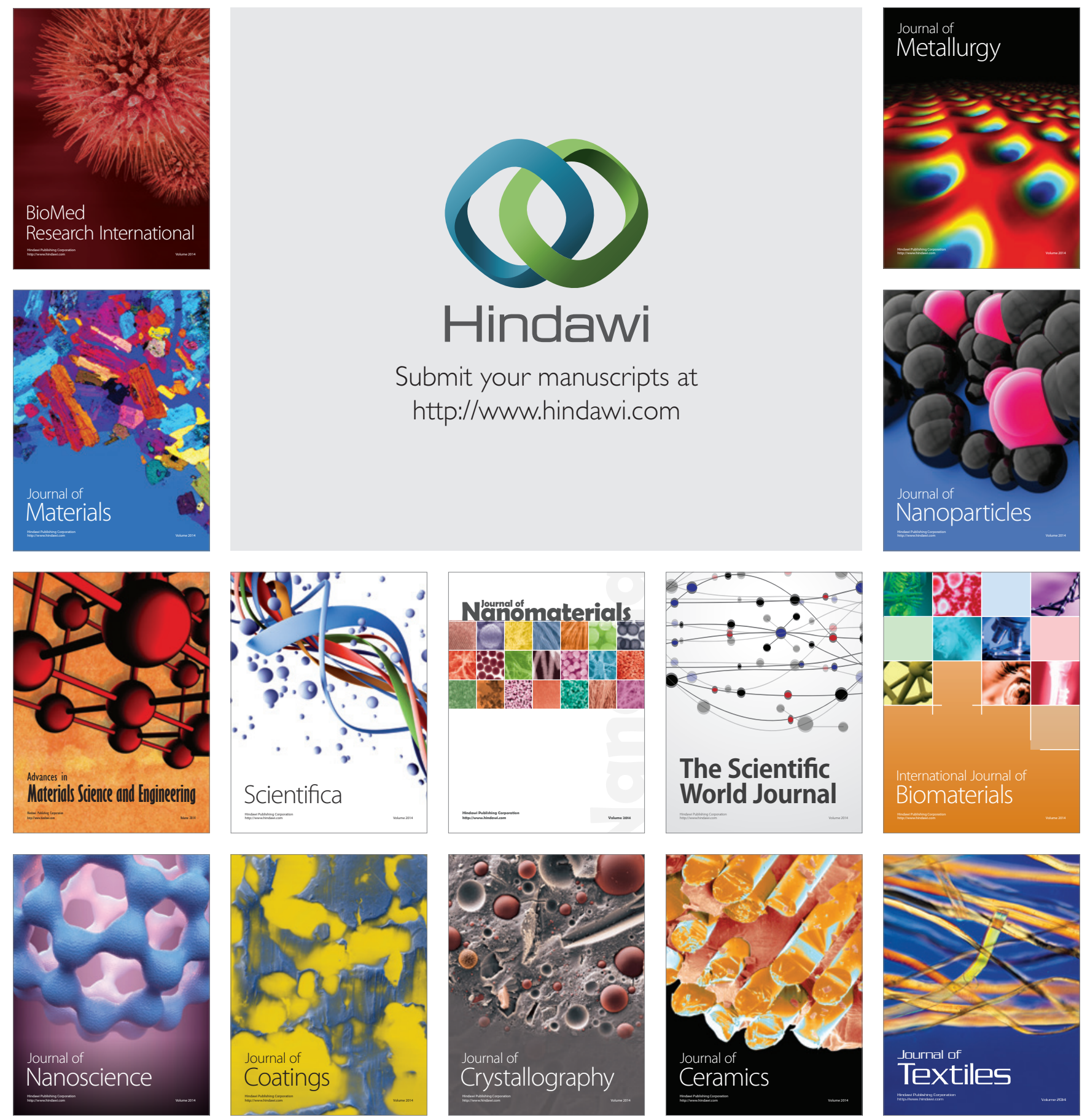